\title{
The Stock Market in the Overlapping Generations
}

\section{Model with Production}

\author{
Michael MAGILL \\ Department of Economics \\ University of Southern California \\ e-mail: magill@usc.edu \\ Martine QUINZII \\ Department of Economics \\ University of California, Davis \\ e-mail:mmquinzii@ucdavis.edu
}

October 1999

\begin{abstract}
We are grateful to participants in seminars at the University of California, Davis, the University of California, San Diego, the SITE summer workshop, Stanford University, The Conference for Advancement of Economic Theory in Rhodes, for stimulating comments. We especially grateful to Klaus Nehring for helpful discussions and comments.
\end{abstract}




\section{Introduction}

How much of the recent stock market boom is attributable to the baby boom generation? How will the market respond when this generation comes to retire? Is the unusual period of expansion that we are experiencing attributable to these demographic forces? These are questions of much current interest, to which economists do not have good answers, due in large part to the lack of appropriate models. Diamond's (1965) overlapping-generations model with production is the model which comes closest to having the necessary ingredients for throwing light on these issues: it relates demographic structure to capital accumulation and hence output, and has a market for capital goods which some authors interpret as a stock market.

In practice however the stock market and the second-hand capital goods markets are very different markets, both in size and in characteristics. The total capitalization on the US stock market is measured in trillions, whereas millions would probably be a better unit for the secondhand capital goods market. The stock market is perhaps the most active and liquid of all markets in a capitalist economy and is deemed by the academic profession to satisfy "the efficient markets hypothesis"; by contrast the market for used capital goods is notoriously thin and imperfect. The premiss of this paper is that the stock market exists because transferring ownership of firms through second-hand capital markets is unpractical. Its conclusion is that explicitly modeling the stock market in a Diamond model, along with the reason which justifies its existence, changes the behavior of the model in important ways and yields new insights into the role of the stock market as a mechanism for the intergenerational transfer of firms.

Why is a second-hand market unpractical for transferring the ownership of firms? Among the many reasons that can be found, firm specificity of capital seems to be one of the most important. In a typical firm there is much investment in "software" — organizational procedures, specific knowledge of a market or a technology — which take much labor and resources to create, and which is essentially lost if the firm is liquidated. Even the "hardware" part - the plant and machinery - usually needs to be adapted to the specific technology used by the firm and is of little value for use by other businesses or consumers. To quote Tobin (1998, p. 147). "The various physical assets of a business enterprise are often designed, installed and used in complex combinations specific to the technology. It is costly or impossible to detach and move individual assets or to apply them to alternative purposes." Thus in order to retain its value as an accumulated sum of tangible and intangible investments, a firm must be kept intact in its entirety, even when its ownership needs to change hands because of the finite life of the "actors", which contrasts with the long-lived nature 
of the firm's capital.

If a firm cannot be carved up and sold in small pieces without loosing value, then an institution needs to come to the rescue to restore liquidity of ownership and competition, since selling large indivisible objects makes for illiquid and imperfectly competitive markets. The institution which emerged in response to this need for liquid ownership of illiquid investments was the corporate form of organization: by permitting the firm to become a separate legal entity which issues equity shares to its future income stream, ownership of firms can be transferred in perfectly divisible amounts across an indefinite succession of finite-lived shareholders, while retaining in perpetuity the full physical and organizational entity of the firm. ${ }^{1}$

This stylized picture does not contradict the fact that in the normal course of business, firms change some of their equipment which may be useful for other businesses, and that a second-hand market for capital goods exists. However this market is not the market on which the ownership of firms is transferred, although it does help recover some value - typically a small percentage of its replacement cost - when an unsuccessful firm is liquidated.

To capture these stylized facts in the framework of a model, we retain Diamond's assumption that capital is durable, and modify his model by assuming that capital investment is irreversible: once resources have been invested in a particular firm, these resources are "sunk" in that firm and cannot be transformed back into the consumption good, or transferred from one firm to another without incurring significant adjustment costs. For simplicity these adjustment costs are taken to be infinite, thereby factoring out from the model the second-hand capital goods market which, as we just argued, is limited. In this setting firms become infinite-lived corporations whose ownership shares are traded on a stock market.

This paper does not claim to give precise answers to the topical questions raised at the beginning on the relationship between demography, stock prices and investment. We believe however that explicitly introducing a stock market into the Diamond model is a step in the right direction. In order to compare the stock market model with the standard model we retain the assumptions of Diamond on the characteristics of the economy: ${ }^{2}$ in particular we adopt the simplest demographic structure in which population grows at a constant rate - which obviously excludes consideration of the effects of a "baby boom".

\footnotetext{
${ }^{1}$ Blackstone (1765) in his Commentaries on the Laws of England, (Book I, Chapter XVIII), referred to "perpetual succession" as the "very end of incorporation: for there can not be a succession forever without an incorporation". He explained "it has been found necessary when it is for the advantage of the public to have any particular rights kept on foot and continued, to constitute artificial persons, who may maintain a perpetual succession, and enjoy a kind of legal immortality. These artificial persons are called... corporations."

${ }^{2}$ See for example Azariadis (1993) and Blanchard-Fischer (1989) for a systematic analysis of the Diamond model.
} 
Replacing the second-hand capital goods market by a stock market will only make a difference if in the resulting equilibrium the equity prices of firms differ from the replacement value of their capital. In the absence of frictions on new investment, the financial value of a firm cannot exceed its replacement cost: for the young agents could always recreate the capital of the firm out of current output if it were less expensive to do so, and the firm would not sell at its current equity price. However, the assumption that previously installed capital is a sunk cost permits the equity price to be less than the replacement cost without creating arbitrage opportunities: buying a firm on the stock market and liquidating its capital on a second-hand market is always a loosing strategy in our model. It is clear that in the more realistic case where the liquidation value is much lower than the replacement cost, but not zero, the financial value can still be lower than the replacement cost, with a lower bound at the liquidation value of the capital. Thus the assumption that investment is irreversible makes it possible for Tobin's $q$ - the ratio of the stock market value of the firm to the replacement cost of its capital - to be less than 1 .

The impossibility of arbitraging by buying a firm and liquidating its capital is not however sufficient to ensure that, in equilibrium, the equity price can be less than the replacement value of capital. For we need to be sure that such a difference does not discourage investment to the point where production must come to a halt because capital has not been maintained or increased sufficiently to meet the needs of the growing population: indeed the first step in the paper is to show that having equity prices less than the replacement cost of their capital is compatible with positive investment by firms (Proposition 1). It is at this point that the analysis differs in crucial ways from the traditional Tobin's $q$ theory. For we find that investment is positive only if investors (shareholders) expect the difference between equity price and value of the invested capital to be a lump-sum discount which is subtracted from the replacement value of the firm. Thus shareholders do not expect to resell the firm for a percentage of its value as in Tobin's framework - rather they expect to sell it for its full value less a discount. The valuation of equity in this model is akin to a two-part tariff, with a marginal price of one for the (depreciated) capital and a negative fixed part which we call the discount. To ensure the equality between the rates of returns on equity and the bond, the discount must satisfy a rate-of-return equation and not be too large (in a sense made precise in Proposition 2).

This "two-part tariff" valuation formula for the equity of firms leads to an interesting new mechanism by which the stock market influences investment, especially for the class of economies regarded by many economists (see e.g. Abel et al (1989)), as empirically the most relevant, namely those characterized by underaccumulation. For in such economies the savings of the young are 
"scarce" and, in the standard Diamond model, do not suffice to lead the economy to the Golden Rule. However when there is a discount on the equity prices of firms, this discount - no matter how small - frees some of the scarce savings of the young and enables them to be used to purchase new investment rather than paying for previously installed capital. Although the investment behavior of firms is the same as in Diamond's model, it is "as if" there were more savings in the economy (thanks to the discount), so that the equality "savings = investment" occurs at a lower interest rate than in the Diamond equilibrium. As a result there is more investment, and hence more output, wages and savings in the next period, and this virtuous cycle fuels a sufficient increase in investment to lead the economy to the Golden Rule rather than to the Diamond steady state. In an economy with underaccumulation, convergence to the Diamond steady state is exceptional, for it is saddle-point stable and is reachable only if the discount is zero at all times: for every other initial condition a stock market equilibrium converges to the Golden Rule. Since the Golden Rule is the efficient steady state, the dynamic analysis reveals a new benefit derived from the stock market as an instrument for the transfer of ownership of firms between generations, which is separate from its liquidity role discussed above, and its risk-sharing role which typically takes preeminence in models of financial economics such as CAPM, but which is inevitably absent in the simple deterministic framework of this model.

The idea that frictions, or adjustment costs, may importantly influence the process of capital accumulation has a long tradition in economics (Lucas (1967), Gould (1968), Uzawa (1969), Kydland-Prescott (1982)) and some authors have derived from such adjustment costs the existence of a Tobin's $q$ different from 1 (Hayashi (1982), Basu (1987), Abel (1999)). These papers study the effects of adjustment costs in installing new capital, and typically assume that these costs are convex. Our approach is different in that it focuses on the adjustment costs that would need to be incurred if previously installed capital were to be put at an alternative use, rather than on the cost of installing new capital.

Since the equilibrium of the model yields both the stock market valuations of firms as well as endogenously determined dividend streams, it is natural to return to the unsettled question of whether or not "rational bubbles" on equity can occur in equilibrium. If it is by now wellunderstood that under natural assumptions on the primitives of the economy, bubbles on equity cannot occur in infinite-lived agent models, ${ }^{3}$ the results for the OLG model with production are much less clear, if only because the Diamond model does not have an explicit stock market. The study of bubbles in the OLG model has centered on the existence of bubbles on money, modeled

\footnotetext{
${ }^{3}$ See for example Tirole (1982), Magill-Quinzii (1996), Woodford-Santos (1998).
} 
as an asset with a zero exogenous dividend stream, and, as Tirole (1985) and Weil (1987) showed, sustainable bubbles can only exist in the case of overaccumulation, albeit with no real effect on the long-run dynamics of the equilibrium. The intuition that came out of these studies is that bubbles can arise in economies with abundant savings, but that they do not succeed in siphoning off the excess savings, except on one highly exceptional trajectory.

Paradoxically, however, we find that bubbles on equity also occur in economies with underaccumulation. Only in the exceptional case in which the discount is zero and the equilibrium coincides with the Diamond equilibrium does the equity price of a firm coincide with its fundamental value (the discounted value of its dividends). On every other path, despite the fact that firms are "cheap" when compared to the cost of their capital, the equity price of a firm exceeds its fundamental value. The fact that equity contracts are transferred from one generation to the next gives them a transmission value, over and above the value of their dividends, and this model suggests that the fundamentalist view of standard finance theory should perhaps be broadened to take this additional source of value into account.

\section{The Stock Market Model}

Consider an OLG model with production of the most standard form. At each date $t, N_{t}$ young agents are born who will live for two periods, $t$ and $t+1$. Each of these agents is endowed with 1 unit of labor when young and has no initial resources when old. Agents of all generations are identical, with the same endowment (1 unit of labor when young) and the same preferences, represented by a utility function $u\left(c_{0}^{t}, c_{1}^{t}\right)$ over consumption streams $c^{t}=\left(c_{0}^{t}, c_{1}^{t}\right)$, where $c_{s}^{t}, s=0,1$, represents the consumption at date $t+s$ of an agent born at date $t$. The population is assumed to grow at the exogenous rate $n,(n \geq 0)$, i.e. $N_{t+1}=(1+n) N_{t}$.

On the production side, there is a collection of $J$ firms $(j=1, \ldots J)$, all firms producing at each date $t$ an all-purpose good - which we will call the output - from capital and labor, with

the time-invariant technology $Y_{t}^{j}=F\left(K_{t}^{j}, L_{t}^{j}\right)$ where the function $F$ is the same for all firms and is smooth, concave, strictly increasing and homogeneous of degree 1 . The output of firms can be used either directly for consumption or to create new capital, where it takes one unit of the good to produce one unit of new capital for any firm. Capital in each firm is durable and depreciates at the rate $\beta(0<\beta<1)$ and needs to be installed one period before it is used: thus the capital $K_{t}^{j}$ used by firm $j$ is the capital that it has carried over from date $t-1$.

The model that we propose differs from that of Diamond (1965) by the assumption that capital 
once installed in a firm cannot be "unbolted" and transformed back into the homogeneous current output, without incurring significant adjustment costs — which for simplicity we take to be infinite. Thus once capital has been installed in a firm, it cannot be used for consumption, nor can it be used as new investment (i.e. additional capital) by any other firm: in short, it is sunk in the firm. As indicated in the introduction this assumption is meant to capture the fact that many resources invested in a firm have to be adapted in a way which is firm specific to make the whole production process function smoothly and efficiently. Since the precise way in which the resources have been adapted typically makes them inappropriate for use by other firms, such installed capital has limited value on a resale market. For example, software written specifically for a firm and incorporating its specific needs may be very expensive - it consumes great deal of labor not used for producing the consumption good - but has essentially no resale value. Even those capital good which have a resale value, for example plant and machinery, usually have a low value on the used capital market relative to their replacement cost, since significant "adjustment costs" have to be incurred to adapt them for use by other firms. To capture this phenomenon in a simple way, we study the theoretical limit in which installed capital of a firm is completely firm specific, so that no part of it has a positive resale value on the second-hand market.

In such an economy capital accumulation will only take place if the market structure permits firms to be infinitely lived. Invested capital has no value if the firm is liquidated, and has value only if the firm retains its identity as an income generating unit in the economy. The natural market structure which permits short-lived agents to transfer ownership of long-lived firms from one generation to the next is an equity market for ownership shares of firms. Thus to have a market structure consistent with the firm specificity of capital, we assume that each firm is a corporation with an infinite life whose ownership shares are transmitted from one generation to the next through the stock market. Let $Q_{t}^{j}$ denote the price of the $j^{\text {th }}$ firm's equity at date $t$.

At each date $t$, in addition to the stock market, there are three other markets: a market for current output, a labor market, and a bond market. Since this is a real (as opposed to a monetary) model, the price of a unit of current output is normalized to be 1 . Let $w_{t}$ denote the wage rate at date $t$ on the labor market on which the (homogeneous) services of labor supplied by the young generation are sold to the firms. The bond market permits young agents to save for their retirement and allows firms to finance their capital investment: we let $r_{t+1}$ denote the interest rate on a loan from date $t$ to date $t+1$. Let $\left(1,\left(Q_{t}^{j}\right)_{j=1}^{J}, w_{t}, r_{t+1}\right)$ denote the vector of prices on these four markets at date $t(t=0,1, \ldots)$. 
Agent's maximum problem. The representative young agent born at date $t$ purchases a portfolio of securities

$$
\left(z_{t}, \theta_{t}^{1}, \ldots, \theta_{t}^{J}\right)
$$

consisting of an amount $z_{t}$ of bonds and share $\theta_{t}^{j}$ of firm $j$ (for $j=1, \ldots, J$ ) so as to maximize lifetime utility $u\left(c_{0}^{t}, c_{1}^{t}\right)$ subject to the budget constraints

$$
\begin{aligned}
c_{0}^{t} & =w_{t}-z_{t}-\sum_{j=1}^{J} \theta_{t}^{j} Q_{t}^{j} \\
c_{1}^{t} & =z_{t}\left(1+r_{t+1}\right)+\sum_{j=1}^{J} \theta_{t}^{j}\left(D_{t+1}^{j}+Q_{t+1}^{j}\right)
\end{aligned}
$$

where $D_{t}^{j}$ denotes the dividend paid by firm $j$ at date $t$. The agent takes the prices $\left(1,\left(Q_{t}^{j}\right)_{j=1}^{J}, w_{t}, r_{t+1}\right)$ as given, and correctly anticipates the next period dividends and prices of the firms $\left(D_{t+1}^{j}, Q_{t+1}^{j}\right)_{j=1}^{J}$. The maximum problem of the agent has a solution if and only if the no-arbitrage condition between the stock and the bond market

$$
Q_{t}^{j}=\frac{1}{1+r_{t+1}}\left(D_{t+1}^{j}+Q_{t+1}^{j}\right), \quad j=1, \ldots, J
$$

holds for the equity price of each firm. Since by (2) the rate of return on the bond and each of the equity contracts is the same, the agent is indifferent between investing in any firm or investing in the bond market: all that matters is the total sum invested in the capital markets, namely the agent's total savings $s_{t}$. When (2) holds the budget equations (1) can be written as

$$
\begin{aligned}
& c_{0}^{t}=w_{t}-s_{t} \\
& c_{1}^{t}=s_{t}\left(1+r_{t+1}\right)
\end{aligned}
$$

where

$$
s_{t}=z_{t}+\sum_{j=1}^{J} \theta_{t}^{i} Q^{j}
$$

The maximizing behavior of the agent is summarized by the savings function $s: \mathbb{R}_{t}^{2} \longrightarrow \mathbb{R}$ defined by

$$
s\left(r_{t+1}, w_{t}\right)=w_{t}-c_{0}\left(r_{t+1}, w_{t}\right)
$$

where $\left(c_{0}(r, w), c_{1}(r, w)\right)$ is the solution of the problem of maximizing $u\left(c_{0}, c_{1}\right)$ subject to the budget equations (3), or equivalently the solution of the problem

$$
\max _{\left(c_{0}, c_{1}\right) \in \mathbb{R}_{+}^{2}}\left\{u\left(c_{0}, c_{1}\right) \mid c_{0}+\frac{c_{1}}{1+r}=w\right\}
$$

Assumption $\mathcal{C}$. The utility function $u\left(c_{0}, c_{1}\right)$ is such that the induced savings function $s(r, w)$ satisfies 
(a) $0<s_{w}^{\prime}(r, w)<1, \quad \forall(r, w) \gg 0$

(b) $s_{r}^{\prime}(r, w) \geq 0, \quad \forall(r, w) \gg 0$

(a) is the assumption that consumption in each period is a normal good, while (b) implies that when the interest rate increases, the substitution effect dominates the income effect, so that savings increase.

Corporation's decision problem. To make clear how the production, financing, investment and transfer of ownership of corporation $j$ from old to young shareholders, takes place during the course of period $t$, it is convenient to divide each period into three subperiods $\left(t_{1}, t_{2}, t_{3}\right)$. In the first subperiod $t_{1}$ the old are owners of the corporation: they bought it in the previous period, at which time they made an investment decision $I_{t-1}$, which, we assume, they financed by borrowing. Thus the corporation has on hand a capital stock $K_{t}^{j}$. They (or a manager) hire labor $L_{t}^{j}$ and produce the output $F\left(K_{t}^{j}, L_{t}^{j}\right)$, out of which they pay the wages $w_{t} L_{t}^{j}$ to the young workers and reimburse $\left(1+r_{t}\right) I_{t-1}$ to the bondholders, leaving them with the dividend

$$
D_{t}^{j}=F\left(K_{t}^{j}, L_{t}^{j}\right)-w_{t} L_{t}^{j}-\left(1+r_{t}\right) I_{t-1}^{j}
$$

In subperiod $t_{2}$, since production has taken place, the firm's capital stock has depreciated to the amount $(1-\beta) K_{t}^{j}$. The old agents sell their shares of the firm on the stock market to the young for the price $Q_{t}^{j}$. Finally, in subperiod $t_{3}$, the young who are now the new owners of the firm, decide on the investment $I_{t}^{j}$ to make, thereby determining the capital stock $K_{t+1}^{j}=(1-\beta) K_{t}^{j}+I_{t}^{j}$ that they will carry over to period $t+1$.

Thus during period $t$, two decisions are made by the corporation: how much labor to hire $\left(L_{t}^{j}\right)$ and how much to invest in new capital $\left(I_{t}^{j}\right)$. Given the timing described above $L_{t}^{j}$ is chosen by the old agents who have already chosen $I_{t-1}^{j}$ and $K_{t}^{j}$ in the previous period and will receive

$$
F\left(K_{t}^{j}, L_{t}^{j}\right)-w_{t} L_{t}^{j}-\left(1+r_{t}\right) I_{t-1}^{j}+Q_{t}^{j}\left((1-\beta) K_{t}^{j}\right)
$$

as dividend and capital value from the firm. The optimal choice of $L_{t}^{j}$ is characterized by

$$
F_{L}^{\prime}\left(K_{t}^{j}, L_{t}^{j}\right)=w_{t}
$$

This is the decision made in the first subperiod: let us now move to the second subperiod $t_{2}$ in which the firm is sold by the old at the price $Q_{t}^{j}\left((1-\beta) K_{t}^{j}\right)$. Since the old agents disappear at the end of the period, they have the option of abandoning their capital and can thus not be forced to 
"pay" a price to sell their firm: thus $Q_{t}^{j} \geq 0$. On the other hand the young will not accept to buy the firm on the stock market if the equity price exceeds the replacement cost $(1-\beta) K_{t}^{j}$ of the firm on the new capital goods market. Thus the price must always satisfy

$$
0 \leq Q_{t}^{j}\left((1-\beta) K_{t}^{j}\right) \leq(1-\beta) K_{t}^{j}
$$

if the firm is to be transferred across the generations. Assuming that the firm is transferred, competition among the young agents will drive the equity price to the point where the return on the firm is equal to the common rate of return $r_{t+1}$ on the financial markets

$$
\begin{aligned}
Q_{t}^{j}\left((1-\beta) K_{t}^{j}\right)=\frac{1}{1+r_{t+1}} \max _{\left(I_{t}^{j}, L_{t+1}^{j}\right) \in \mathbb{R}_{+}^{2}\{} & F\left((1-\beta) K_{t}^{j}+I_{t}^{j}, L_{t+1}^{j}\right)-w_{t+1} L_{t+1}^{j} \\
& \left.-\left(1+r_{t+1}\right) I_{t}^{j}+Q_{t+1}^{j}\left((1-\beta) K_{t+1}^{j}\right)\right\}
\end{aligned}
$$

where $K_{t+1}^{j}=(1-\beta) K_{t}^{j}+I_{t}^{j}$. To make their optimal choice of investment $I_{t}^{j}$ (in subperiod $\left.t_{3}\right)$ the young agents must anticipate how $Q_{t+1}^{j}$ depends on $K_{t+1}^{j}$ : thus anticipation functions $Q_{t}^{j}: \mathbb{R}_{+} \longrightarrow \mathbb{R}_{+}, t \geq 0$ are needed to describe how the economy functions and, in order to be correct, these anticipations must satisfy the functional equation (8).

Proposition 1 (Equity Pricing Formula): A necessary condition for a solution of the functional equation (8) to be compatible with $I_{t}^{j}>0$ for all $t \geq 0$ is that there exist a sequence of constants $\left(V_{t}^{j}\right)_{t \geq 0}$ such that

(i) $Q_{t}^{j}(\xi)=\xi-V_{t}^{j}$

(ii) $V_{t+1}^{j}=\left(1+r_{t+1}\right) V_{t}^{j}$

PROOF: (i) Let (8) be written as

$Q_{t}^{j}(\xi)=\frac{1}{1+r_{t+1}} \max _{\left(I_{t}^{j}, L_{t+1}^{j}\right) \in \mathbb{R}_{+}^{2}}\left\{F\left(\xi+I_{t}^{j}, L_{t+1}^{j}\right)-w_{t+1} L_{t+1}^{j}-\left(1+r_{t+1}\right) I_{t}^{j}+Q_{t+1}^{j}\left((1-\beta)\left(\xi+I_{t}^{j}\right)\right)\right\}$

and let $\left(I_{t}^{j *}(\xi), L_{t+1}^{j *}(\xi)\right)$ denote a positive solution to the maximum problem in (9). Then the first-order conditions

$$
\begin{gathered}
F_{L}^{\prime}\left(\xi+I_{t}^{j *}(\xi), L_{t+1}^{j *}(\xi)\right)-w_{t+1}=0 \\
F_{K}^{\prime}\left(\xi+I_{t}^{j *}(\xi), L_{t+1}^{j *}(\xi)\right)-\left(1+r_{t+1}\right)+(1-\beta) Q_{t+1}^{j \prime}\left((1-\beta)\left(\xi+I_{t}^{j *}(\xi)\right)=0\right.
\end{gathered}
$$

must be satisfied. Differentiating (9), and using (10) and (11) (i.e. the envelope theorem) gives

$$
Q_{t}^{j \prime}(\xi)=\frac{1}{1+r_{t+1}}\left(F_{K}^{\prime}\left(\xi+I_{t}^{j *}(\xi), L_{t+1}^{j *}(\xi)\right)+(1-\beta) Q_{t+1}^{j \prime}\left((1-\beta)\left(\xi+I_{t}^{j *}(\xi)\right)\right)\right.
$$


By $(11), Q_{t}^{j \prime}(\xi)=1$ for all $\xi>0$. Integrating gives $Q_{t}^{j}(\xi)=\xi-V_{t}^{j}$ for some constant $V_{t}^{j}$.

(ii) Given this form for $Q_{t}^{j}$ and $Q_{t+1}^{j}$, (9) becomes

$$
-\left(1+r_{t+1}\right) V_{t}^{j}=F\left(\xi+I_{t}^{j *}(\xi), L_{t+1}^{j *}(\xi)\right)-w_{t+1} L_{t+1}^{j *}(\xi)-\left(r_{t+1}+\beta\right)\left(\xi+I_{t}^{j *}(\xi)\right)-V_{t+1}^{j}
$$

while (11) reduces to

$$
F_{K}^{\prime}\left(\xi+I_{t}^{j *}(\xi), L_{t+1}^{j *}(\xi)\right)=r_{t+1}+\beta
$$

Substituting (10) and (13) into (12) and using the homogeneity of degree one of $F$ gives (ii).

Thus Proposition 1 implies that young agents can only be expected to make a positive investment in their firm if they anticipate that they will recover the (depreciated) cost of their investment in the resale value of their firm. However, this does not require that the stock market value of the firm coincide with the replacement value of its capital: since the constants $V_{t}^{j}$ in Proposition 1 must be non-negative (for (7) to be satisfied), the valuation (i)

$$
Q_{t+1}^{j}\left((1-\beta) K_{t+1}^{j}\right)=(1-\beta) K_{t+1}^{j}-V_{t+1}^{j}
$$

implies that the stock-market value of the firm can be at a discount relative to its replacement cost. In the next proposition we show that if there is to be positive investment, the discount $V_{t+1}^{j}$ on firm $j$ at date $t+1$ must not be too large.

Consider therefore the investment decision $I_{t}^{j}$ of the young at date $t$ who face the current interest rate $r_{t+1}$ and anticipate the wage and discount $\left(w_{t+1}, V_{t+1}^{j}\right)$ next period. This investment decision cannot be separated from next period's labor choice $L_{t+1}^{j}$, which in view of (6) is a choice of capital-labor ratio $\left(F_{L}^{\prime}\right.$ is homogeneous of degree 0$)$. Let us therefore introduce the production function per unit of labor

$$
f(k)=F(k, 1)
$$

which is common to all firms. ${ }^{4}$

Proposition 2 (Positive Investment): There is a positive solution $I_{t}^{j}$ to the optimal choice of investment in firm $j$ at date $t$ if and only if $\left(r_{t+1}, w_{t+1}, V_{t+1}^{j}\right)$ satisfy

( $\alpha) 0 \leq V_{t+1}^{j} \leq(1-\beta)^{2} K_{t}^{j}$

( $\beta) w_{t+1}=f\left(k_{t+1}\right)-\left(\beta+r_{t+1}\right) k_{t+1}$ where $k_{t+1}$ is the solution to

\footnotetext{
${ }^{4}$ Recall that with $k=K / L, F_{K}^{\prime}(K, L)=f^{\prime}(k), F_{L}^{\prime}(K, L)=f(k)-k f^{\prime}(k)$.
} 
$(\gamma) f^{\prime}\left(k_{t+1}\right)=\beta+r_{t+1}$

If these conditions hold, then any $I_{t}^{j}>0$ combined with a choice of $L_{t+1}^{j}$ such that $K_{t+1}^{j} / L_{t+1}^{j}=$ $k_{t+1}$, where $k_{t+1}$ is defined by $(\gamma)$, is optimal.

Proof: Since we have assumed free disposal of firms, young agents at date $t$ choose $\left(I_{t}^{j}, L_{t+1}^{j}\right)$ so as to maximize their profit $\pi_{t+1}^{j}=D_{t+1}^{j}\left(I_{t}^{j}, L_{t+1}^{j}\right)+\max \left\{0,(1-\beta) K_{t+1}^{j}-V_{t+1}^{j}\right\}$. Using the equation $I_{t}^{j}=K_{t+1}^{j}-(1-\beta) K_{t}^{j}$ and (5), the expression for $\pi_{t+1}^{j}$ is

$$
\pi_{t+1}^{j}=F\left(K_{t+1}^{j}, L_{t+1}^{j}\right)-w_{t+1} L_{t+1}^{j}-\left(\beta+r_{t+1}\right) K_{t+1}^{j}+\left(1+r_{t+1}\right)(1-\beta) K_{t}^{j}-V_{t+1}^{j}
$$

if $(1-\beta) K_{t+1}^{j}-V_{t+1}^{j} \geq 0$ and

$$
\pi_{t+1}^{j}=F\left(K_{t+1}^{j}, L_{t+1}^{j}\right)-w_{t+1} L_{t+1}^{j}-\left(1+r_{t+1}\right) K_{t+1}^{j}+\left(1+r_{t+1}\right)(1-\beta) K_{t}^{j}
$$

if $(1-\beta) K_{t+1}^{j}-V_{t+1}^{j}<0$.

Suppose that $(\alpha)$ holds: then for any $I_{t}^{j} \geq 0,(1-\beta) K_{t+1}^{j}-V_{t+1}^{j}=(1-\beta)^{2} K_{t}^{j}+(1-\beta) I_{t}^{j}-V_{t+1}^{j} \geq$ 0 , so that the agents maximize (15) on the domain $K_{t+1}^{j} \geq(1-\beta) K_{t}^{j}, L_{t+1}^{j} \geq 0$. It is well known that $(\beta)$ and $(\gamma)$ are necessary and sufficient to have an interior solution to the maximum problem and that the result of the proposition holds.

Let us show that if $(\alpha)$ does not hold then no positive level of investment is optimal. In this case for small $I_{t}^{j},(1-\beta)\left((1-\beta) K_{t}^{j}+I_{t}^{j}\right)<V_{t+1}^{j}$ and $\pi_{t+1}^{j}$ is given by $(16)$. Let $\bar{I}=\frac{V_{t+1}^{j}-(1-\beta)^{2} K_{t}^{j}}{1-\beta}$ denote the smallest investment which gives a non-negative value to the anticipated price (14). Suppose that $\left(I_{t}^{j *}, L_{t+1}^{j *}\right)$ maximize $\pi_{t+1}^{j}$ with $I_{t}^{j}>0$. Either $I_{t}^{j *} \in(0, \bar{I}]$ or $I_{t}^{j *} \in(\bar{I}, \infty)$. In the first case, the implied capital stock $K_{t+1}^{j *}=(1-\beta) K_{t}^{j}+I_{t}^{j *}$, combined with $L_{t+1}^{j *}$, must maximize (16) on the domain $\left[(1-\beta) K_{t}^{j},(1-\beta) K_{t}^{j}+\bar{I}\right]$ and the constraint $K_{t+1}^{j} \geq(1-\beta) K_{t}^{j}$ is not binding. This implies that $\left(w_{t+1}, r_{t+1}\right)$ must be such that

$$
F_{K}^{\prime}\left(K_{t+1}^{j *}, L_{t+1}^{j *}\right) \geq 1+r_{t+1}, \quad F_{L}^{\prime}\left(K_{t+1}^{j *}, L_{t+1}^{j *}\right)=w_{t+1}
$$

Consider the capital-labor ratio $k_{t+1}^{j *}=K_{t+1}^{j *} / L_{t+1}^{j *}$ and large values of capital and labor such that $K_{t+1}^{j} \geq(1-\beta) K_{t}^{j}+\bar{I}$ and $L_{t+1}^{j}=K_{t+1}^{j} / k_{t+1}^{j *}$. Then (15) evaluated at such pairs is equal to

$$
L_{t+1}^{j}\left(f\left(k_{t+1}^{j *}\right)-w_{t+1}-\left(\beta+r_{t+1}\right) k_{t+1}^{j *}\right)+(1-\beta)\left(1+r_{t+1}\right) K_{t}^{j}-V_{t+1}^{j}
$$

which, when (17) holds, can be made arbitrarily large. Thus $I_{t}^{j *} \in(0, \bar{I})$ is not possible.

Suppose $I_{t}^{j *} \in(\bar{I}, \infty)$. Then $\left(K_{t+1}^{j *}, L_{t+1}^{j *}\right)$ must be an interior solution to maximizing (15) on the domain $\left[(1-\beta) K_{t}^{j}+\bar{I}, \infty\right) \times[0, \infty)$. Thus $(\beta)$ and $(\gamma)$ must hold with $k_{t+1}=K_{t+1}^{j *} / L_{t+1}^{j *}$ 
and the profit at date $t+1$ will be $\pi_{t+1}^{j *}=\left(1+r_{t+1}\right)(1-\beta) K_{t}^{j}-V_{t+1}^{j}$. Let us show that the shareholders would be made better off by not investing. If they do not invest they will have $\pi_{t+1}^{j}=\max _{L_{t+1}^{j} \geq 0} F\left((1-\beta) K_{t}^{j}, L_{t+1}^{j}\right)-w_{t+1} L_{t+1}^{j} \geq \widetilde{\pi}_{t+1}^{j}$ where $\widetilde{\pi}_{t+1}^{j}=\widetilde{L}_{t+1}^{j}\left(f\left(k_{t+1}\right)-w_{t+1}\right)$ and $\widetilde{L}_{t+1}^{j}=(1-\beta) K_{t}^{j} / k_{t+1}$. Given that $(\beta)$ and $(\gamma)$ are satisfied $\tilde{\pi}_{t+1}^{j}=\left(\beta+r_{t+1}\right)(1-\beta) K_{t}^{j}$. It is easy to check that when $(\alpha)$ does not hold, $\tilde{\pi}_{t+1}^{j}>\pi_{t+1}^{j *}$ contradicting the optimality of $I_{t}^{j *}$.

Remark: Since $Q_{t+1}^{j}=(1-\beta) K_{t+1}^{j}-V_{t+1}^{j}=(1-\beta)^{2} K_{t}^{j}+(1-\beta) I_{t}^{j}-V_{t+1}^{j}$, condition $(\alpha)$ is equivalent to

$$
Q_{t+1}^{j} \geq(1-\beta) I_{t}^{j}
$$

This condition ensures that the expectation of the young agents at date $t$ - that they will recover the value of their (depreciated) investment $I_{t}^{j}$ in the equity price that they will receive at date $t+1$-is fulfilled.

Equilibrium. An equilibrium is defined as a sequence of prices $\left(w_{t}, r_{t+1},\left(Q_{t}^{j}, V_{t}^{j}\right)_{j=1}^{J}\right)_{t \geq 0}$, consumption-savings-portfolio decisions $\left(c^{t}, s_{t}, z_{t},\left(\theta_{t}^{j}\right)_{j=1}^{J}\right)_{t \geq 0}$ for the sequence of representative consumers born at each date $t \geq 0$, and production-investment decisions $\left(L_{t}^{j}, Y_{t}^{j} ; I_{t}^{j}, K_{t+1}^{j}\right)_{t \geq 0}$ for each of the $J$ corporations, such that consumers maximize their utility subject to their budget constraints (1), firms maximize their profits with price expectations given by (i) - (ii) in Proposition 1, and the labor, output, bond and stock markets clear at every date.

The economy starts at date 0 with firms having initial capital stocks $\left(K_{0}^{j}\right)$ and initial equity prices $\left(Q_{0}^{j}\right)$, or equivalently discounts $V_{0}^{j}=(1-\beta) K_{0}^{j}-Q_{0}^{j}, j=1, \ldots, J$. We are interested in balanced growth equilibria in which all firms invest in each period and firms retain the same relative sizes and the same relative stock market values: such equilibria have the property that they can be transformed into the analysis of the equilibria of an associated aggregate economy. Let us define the economy-wide variables at date $t$

$$
\left(K_{t}, L_{t}, Y_{t}, Q_{t}, V_{t}, I_{t}\right)=\sum_{j=1}^{J}\left(K_{t}^{j}, L_{t}^{j}, Y_{t}^{j}, Q_{t}^{j}, V_{t}^{j}, I_{t}^{j}\right)
$$

Consider initial conditions in which firm $j$ has initial capital and equity value $\left(K_{0}^{j}, Q_{0}^{j}\right)=\lambda_{j}\left(K_{0}, Q_{0}\right)$ which is some share $\lambda_{j}$ of the aggregate capital and stock market value $\left(K_{0}, Q_{0}\right)$. Then if the sequence of prices $\left(w_{t}, r_{t+1}, Q_{t}, V_{t}\right)_{t \geq 0}$ and aggregate production decisions $\left(L_{t}, I_{t}\right) \gg 0$ satisfy (i) and (ii) of Proposition 1 and $(\alpha),(\beta),(\gamma)$ of Proposition 2 with $k_{t+1}=K_{t+1} / L_{t+1}$, then $\left(L_{t}^{j}, I_{t}^{j}\right)=\lambda_{j}\left(L_{t}, I_{t}\right)$, and hence $K_{t+1}^{j}=\lambda_{j} K_{t+1}$, is a sequence of optimal decisions for each firm $j$ in which the discounts $V_{t}^{j}=\lambda_{j} V_{t}$ are correctly anticipated. Since Proposition 1 implies 
that the no-arbitrage equations (2) are satisfied by the dividends and equity prices, the maximizing problem of a representative young agent at each date has a solution summarized by the savings function $s\left(r_{t+1}, w_{t}\right)$. Since we have assumed that all investment is financed by borrowing, equilibrium on the bond market requires $N_{t} z_{t}=I_{t}$, while equilibrium on the stock market requires $N_{t} \theta_{t}^{j}=1, j=1, \ldots, J$. Since all that matters to the representative young agent is the total amount invested in the capital markets - namely $s\left(r_{t+1}, w_{t}\right)$ - and not the proportions between the bond and the stock markets, these two equilibrium conditions can be summarized by the relation $N_{t} s\left(r_{t+1}, w_{t}\right)=I_{t}+Q_{t}$. Finally equilibrium on the labor market requires $L_{t}=N_{t}$, which is satisfied if we require that the capital-labor ratio is equal to the per-capita capital stock i.e $k_{t}=K_{t} / N_{t}$. Let $\left(i_{t}, q_{t}, v_{t}\right)=\frac{1}{N_{t}}\left(I_{t}, Q_{t}, V_{t}\right)$ denote the per-capita investment and stock price variables, then an equilibrium can be summarized in the following reduced form:

Definition 1. A path of savings, capital accumulation, wages and security prices $\left(\left(s_{t}, i_{t}, k_{t+1}\right)\right.$, $\left.\left(w_{t}, q_{t}, v_{t}, r_{t+1}\right)\right)_{t \geq 0}$ with initial conditions $\left(k_{0}, v_{0}\right)$ is an equilibrium of the stock market economy if the following conditions are satisfied for all $t \geq 0$

$$
\begin{array}{ccc}
f\left(k_{t}\right)-k_{t} f^{\prime}\left(k_{t}\right)=w_{t} & \text { (iv) } & q_{t}=(1-\beta) k_{t}-v_{t} \\
f^{\prime}\left(k_{t+1}\right)=\beta+r_{t+1} & \text { (v) } & (1+n) v_{t+1}=\left(1+r_{t+1}\right) v_{t} \\
(1+n) k_{t+1}=(1-\beta) k_{t}+i_{t} & (\text { vi }) & 0 \leq(1+n) v_{t+1} \leq(1-\beta)^{2} k_{t} \\
(\text { vii }) & s\left(r_{t+1}, w_{t}\right)=i_{t}+q_{t}
\end{array}
$$

Conditions (i) - (vi) ensure that firms are maximizing profit at each date with the price anticipations (iv), (v) and that these anticipations are realized, and (vii) summarizes utility maximization of young agents and equilibrium on the financial markets at each date. The consumption of the agents is not explicitly given in the definition of equilibrium: for all agents born at date 0 or thereafter it is given by (3), while the consumption of the old agents at date 0 is given by the initial conditions

$$
c_{0}^{-1}=(1+n)\left(f\left(k_{0}\right)-w_{0}+(1-\beta) k_{0}-v_{0}\right)
$$

The term $\left(1+r_{0}\right) i_{0}$ cancels out since it is a payment made by firms belonging to agents of the old generation to the same old agents in their role as consumer-lenders.

Relation to Tobin's $\boldsymbol{q}$ theory. The concept of a stock market equilibrium in Definition 1 is closely related in spirit to Tobin's $q$ theory where the essential idea is that frictions on the capital market lead to a divergence between the financial (stock market) value of a firm and its real replacement cost, Tobin's $q$ being the ratio of the stock market value to the replacement cost. In our framework the friction which leads to a difference between the financial and real valuations of a firm arises 
from the fact that capital once installed is a sunk cost. Let $\gamma_{t}^{j}$ denote Tobin's $q$ for firm $j$ at date $t$, then

$$
\gamma_{t}^{j}=1-\frac{V_{t}^{j}}{(1-\beta) K_{t}^{j}}
$$

so that $\gamma_{t}^{j}$ is always less than or equal to 1 . In a balanced growth equilibrium all firms have the same $q$ ratio

$$
\gamma_{t}^{j}=\gamma_{t}=1-\frac{v_{t}}{(1-\beta) k_{t}}, \quad j=1, \ldots, J
$$

Note however that the ratio $\gamma_{t}$ is the ex-post result of the firms' choices of investment: firms anticipations of their next period stock prices are not of the form $Q_{t+1}^{j}=\gamma_{t}^{j} K_{t+1}^{j}$. As shown in Proposition 1 such anticipations with $\gamma_{t}^{j} \neq 1$ would be incompatible with positive optimal investment for firms: roughly speaking if $\gamma_{t}^{j}<1$ a firm's investment would be zero, while if $\gamma_{t}^{j}>1$ it would be infinite. In our framework firms' ex-ante anticipations must be of the piecewise linear form $Q_{t+1}^{j}=(1-\beta) K_{t+1}^{j}-V_{t+1}^{j}$ to obtain an equilibrium with positive investment.

As a result our model does not exhibit the direct positive feedback between security prices and investment which is characteristic of Tobin's theory. In our equilibrium, as in that of Diamond, current investment is only influenced by the current interest rate (equation (ii) is the same as in a standard Diamond equilibrium) and is not influenced by the level of security prices $Q_{t+1}^{j}$ next period (as represented by $V_{t+1}^{j}$ ). However since security prices (expressed in per-capita form) evolve according to equations (iv) and (v), a lower interest rate will result in a lower discount $v_{t+1}$ at date $t+1$, and thus by (18) in a higher ratio $\gamma_{t+1}$. Thus lower interest rates, higher investment and higher $q$ ratios go together, but the causality is not the same as that underlying Tobin's $q$ theory where a higher $q$ ratio (or security prices) induces more investment. The study of the dynamics of a stock market equilibrium in the next section will show that while the discounts $V_{t}^{j}$ do not directly affect the current investment decisions of firms, they have a decisive indirect effect by permitting more savings of the young agents to be directed to the bond market (and hence investment) rather than to buying the firms from the old. Thus the discounts on the stock market prices of the firms relative to their replacement costs, by making it cheaper to buy the firms, frees funds which are channeled into increased savings to finance new investment: the result is an equilibrium path with lower interest rates and higher investment.

\section{Dynamics of Stock Market Equilibrium}

In this section we study the long-run dynamics of a stock market equilibrium: as we shall 
see, the most interesting properties arise when the stock market value of each firm differs from its replacement cost. In the model outlined above, this difference between the two values of a firm was traced to an attribute of capital - namely that once installed in a firm, it ceases to be a perfect substitute for current output or current investment. The model however contains as a special case the classic Diamond model in which capital is perfectly malleable and firms can be liquidated at any time, their capital being sold on the market for current output: in this case the financial value of a firm coincides with its replacement cost. More precisely, an equilibrium of the Diamond model corresponds to a stock market equilibrium with initial condition $v_{0}=0$ : equations (iv) and (v) of Definition 1 then imply that $v_{t}=0$ for all $t \geq 0$, so that the equity value of a firm coincides at every date with the replacement value of the capital which is transmitted. In the Diamond model, equations (i) and (ii) of Definition 1 are the equations of profit maximization by firms: combining ((iii)), (iv) with $v_{t}=0$, and (vii) gives

$$
(1+n) k_{t+1}=s\left(r_{t+1}, w_{t}\right)
$$

which is the basic "investment $=$ savings" equation of Diamond's model. Since the properties of a stock market equilibrium in which there is a discount on the equity prices of firms (equilibrium with $v_{0}>0$ ) depend in an essential way on the properties of the underlying Diamond equilibrium $\left(v_{0}=0\right)$, we recall briefly the requisite properties of such an equilibrium.

Diamond Equilibrium. (i) and (ii) in Definition 1 define the wage and interest rate $\left(w_{t}, r_{t+1}\right)$ as functions of the capital-labor ratios $\left(k_{t}, k_{t+1}\right)$ : substituting these functions into (19) gives the first-order difference equation

$$
\Phi\left(k_{t+1}, k_{t}\right) \equiv(1+n) k_{t+1}-s\left(r\left(k_{t+1}\right), w\left(k_{t}\right)\right)=0, \quad \forall t \geq 0
$$

with initial condition $k_{0}>0$, which defines an equilibrium path of capital accumulation of Diamond's model. A Diamond steady state $k_{D}$ is a solution of the equation

$$
(1+n) k_{D}-s\left(r\left(k_{D}\right), w\left(k_{D}\right)\right)=0
$$

For general preferences and technology $(u, F, n)$ there can be several non-trivial steady states and the dynamics $\left(E_{D}\right)$ can exhibit complex behavior. We restrict attention to economies $\mathcal{E}(u, F, n)$ for which there is a unique positive steady state $k_{D}$ and every solution of $\left(E_{D}\right)$ converges to $k_{D}$ : as noted by Galor-Ryder (1989), the standard Assumption $\mathcal{C}$ on preferences combined with Inada (and the usual concavity and homogeneity) conditions on $F$ do not suffice to give this property. 
Assumption $\mathcal{C}(\mathrm{b})$ and the concavity of $F$ imply that there exists a unique solution

$$
k_{t+1}=\phi\left(k_{t}\right)
$$

to the equation $\left(E_{D}\right)$. By the implicit function theorem, $\phi$ is differentiable. An additional assumption is needed to ensure that the graph of $\phi$ cuts the diagonal with a positive slope at a unique $k_{D}>0$. The following condition — which is less restrictive and simpler to verify than the one given by Ryder-Galor (1989) — is sufficient ${ }^{5}$.

Assumption $\mathcal{S}$. Define $S(k)=s(r(k), w(k))$. The function $S(k) / k$ is decreasing for all $k>0$, $\lim _{k \rightarrow 0^{+}} S(k) / k>1+n$, and $\lim _{k \rightarrow+\infty} S(k) / k<1$.

The property $S(k) / k$ decreasing is equivalent to $\log (S(k) / k)$ decreasing and this is equivalent to the elasticity of $S$ being less than one $\left(\eta_{S}=\frac{d S / S}{d k / k}<1\right)$ : a given percentage increase in the capital stock $k$ gives rise to a smaller percentage increase in savings $S$. Although this assumption is a joint assumption on preferences and technology, it can be decomposed into separate assumptions on the consumption and the production sides. For example, it holds if

- $u$ is homothetic and satisfies Assumption $\mathcal{C}$

- $f$ is such that $w(k) / k$ is a decreasing function of $k$ with $\lim _{k \rightarrow 0^{+}} \frac{w(k)}{k}=\infty$ and $\lim _{k \rightarrow \infty} \frac{w(k)}{k}=$ 0

These conditions are satisfied if both $u$ and $F$ are CES with elasticity of substitution greater than or equal to 1 - which includes Cobb-Douglas utility and production functions.

Proposition 3: Under assumptions $(\mathcal{C}, \mathcal{S})$, the Diamond steady-state capital $k_{D}$ is globally stable for the dynamics $\left(E_{D}^{\prime}\right)$ : for any initial condition $k_{0}$, the per-capita capital stock on an equilibrium trajectory of the Diamond economy converges to $k_{D}>0$.

Proof: See Appendix.

Typically the Diamond steady state is not efficient since there is another steady state which sustains a higher permanent level of per-capita consumption. A permanent level of per-capita consumption and capital $\left(c_{1}, c_{2}, k\right)$ is feasible if

$$
c_{1}+\frac{c_{2}}{1+n}=f(k)-(n+\beta) k
$$

\footnotetext{
${ }^{5}$ A similar assumption was used by Weil (1987). For sake of completeness we prove in Appendix that assumption $\mathcal{S}$ implies uniqueness and global stability of the Diamond steady state.
} 
The steady state $k^{*}$ which maximizes permanent per-capita consumption $c_{1}+\frac{c_{2}}{1+n}$ is called the Golden Rule steady state and is characterized by

$$
f^{\prime}\left(k^{*}\right)=n+\beta \Longleftrightarrow r\left(k^{*}\right)=n
$$

The Golden Rule $k^{*}$ is determined purely by technological $(f, \beta)$ and demographic factors $(n)$ : the Diamond steady state $k_{D}$ defined by (20) depends in addition on agents' preferences (savings behavior). Thus for typical economies $k_{D} \neq k^{*}$ so that for most economies the Diamond steady state is inefficient. When $k_{D}<k^{*}$, the interest rate $r_{D}=f^{\prime}\left(k_{D}\right)-\beta$ at the Diamond steady state exceeds the Golden Rule interest rate $r^{*}=f^{\prime}\left(k^{*}\right)-\beta=n$. The Diamond economy converges to a steady state of underaccumulation characterized by a low level of capital, low output and a high interest rate. Under assumption $\mathcal{S}, k_{D}<k^{*}$ is equivalent to $s\left(r\left(k^{*}\right), w\left(k^{*}\right)\right)<(1+n) k^{*}$, so that an alternative definition of underaccumulation is that the savings of the consumers at the prices $\left(r\left(k^{*}\right), w\left(k^{*}\right)\right)$ at the Golden Rule are not sufficient to sustain the Golden Rule capital stock. When $k_{D}>k^{*}, r_{D}<n$ and $s\left(r\left(k^{*}\right), w\left(k^{*}\right)>(1+n) k^{*}\right.$ so that the savings of consumers at $k^{*}$ could "buy" more capital than $k^{*}$ : the Diamond economy converges to a steady state of overaccumulation characterized by a high level of capital, a low interest $r_{D}$ and high output level $y_{D}$, much of which is absorbed by the need to maintain the capital stock rather than being used for consumption.

Stock Market Equilibrium. In the general case where $v_{0} \neq 0$, a stock market equilibrium can also be reduced to the solution of a difference equation describing the path of capital accumulation $\left(k_{t}\right)_{t \geq 0}$ : from this path the other equilibrium quantities and prices can in turn be derived. As before equations (i) and (ii) of Definition 1 define the wage and interest rate. Equations (iii), (iv) and (vii) describe how the savings $s\left(r_{t+1}, w_{t}\right)$ of the young at date $t$ are used to finance new investment $\left(i_{t}=(1+n) k_{t+1}-(1-\beta) k_{t}\right)$ and to purchase the firms on the equity market $\left(q_{t}=(1-\beta) k_{t}-v_{t}\right)$ implying

$$
(1+n) k_{t+1}=s\left(r_{t+1}, w_{t}\right)+v_{t}
$$

Thus when $v_{t}>0$, the (per capita) capital stock that young agents are able to acquire for use in the subsequent period $\left((1+n) k_{t+1}\right)$, exceeds their savings because firms are sold on the equity market with a discount relative to their replacement cost. The discount $v_{t}$ in essence acts like an additional "source of funds" that enables them to finance a higher level of capital accumulation than would be warranted by their savings in a Diamond equilibrium, where firms are sold for their replacement cost.

To guarantee that there is no-arbitrage the evolution of the discount $v_{t}$ must satisfy equation 
(v). If $(21)$ is used to define the discount $v_{t}$ as a function of $\left(k_{t+1}, k_{t}\right)$,

$$
v_{t}=v\left(k_{t+1}, k_{t}\right) \equiv(1+n) k_{t+1}-s\left(r\left(k_{t+1}\right), w\left(k_{t}\right)\right)
$$

then a stock market equilibrium is a solution of the second-order difference equation in $k_{t}$

$$
(1+n) v\left(k_{t+2}, k_{t+1}\right)=\left(1+r\left(k_{t+1}\right)\right) v\left(k_{t+1}, k_{t}\right)
$$

with initial condition $\left(k_{1}, k_{0}\right)$ satisfying $k_{0}>0$ and $v\left(k_{1}, k_{0}\right) \geq 0$. In order that the young have the incentive to undertake positive investment in their firms at each date, the inequality (vi) of Definition 1 must be satisfied at every date, or equivalently $\left(1+r\left(k_{t+1}\right)\right) v\left(k_{t+1}, k_{t}\right) \leq(1-\beta)^{2} k_{t}$. Thus the feasible initial conditions for a stock market equilibrium with positive investment are defined by the inequality

$$
0 \leq\left(1+r\left(k_{1}\right) v\left(k_{1}, k_{0}\right) \leq(1-\beta)^{2} k_{0}\right.
$$

A steady state solution of $\left(E_{S}\right), k_{t}=k, \forall t \geq 0$, must satisfy

$$
(n-r(k)) v(k, k)=0
$$

and the initial condition

$$
0 \leq v(k, k) \leq \frac{(1-\beta)^{2}}{1+n} k
$$

Under Assumptions $(\mathcal{C}, \mathcal{S})$, there are only two positive solutions of $(22)$ : the Diamond steady state given by $v\left(k_{D}, k_{D}\right)=0$ and the Golden Rule defined by $r\left(k^{*}\right)=n . \quad k_{D}$ always satisfies $\left(\mathrm{IC}^{\prime}\right)$. However $k^{*}$ is not a steady state equilibrium of an economy with overaccumulation, since $v\left(k^{*}, k^{*}\right)<0$. For an economy with underaccumulation $v\left(k^{*}, k^{*}\right)>0$, but the characteristics $(u, F, n)$ of the economy must be such that

$$
v^{*}=(1+n) k^{*}-s\left(r\left(k^{*}\right), w\left(k^{*}\right)\right) \leq \frac{(1-\beta)^{2}}{1+n} k^{*}
$$

so that the right side of $\left(\mathrm{IC}^{\prime}\right)$ is satisfied, namely that the young have the incentive to undertake positive investment at $k^{*}$. Thus there is a limit to the extent to which the discount on equity can make up for the deficiency in savings needed to sustain the Golden Rule.

This condition can also be written as

$$
s\left(r\left(k^{*}\right), w\left(k^{*}\right)\right) \geq i^{*}+i^{*} \frac{(1-\beta)}{1+n}
$$

where $i^{*}=(n+\beta) k^{*}$ is the (per-capita) investment needed to sustain the Golden Rule: thus, while the savings of the young may not be sufficient to cover the combined costs of new investment and 
installed capital at replacement value, they must be sufficient to cover current new investment and the depreciated investment of the previous period.

Assumption $\mathcal{S}^{*}$. The characteristics of the economy $(u, F, n)$ are such that $(23)$ is satisfied.

A stock market equilibrium can also be characterized by the pair of equations $(\mathrm{v},(21))$ : this leads to the following first-order difference equation in $\left(k_{t}, v_{t}\right)$

$$
\begin{aligned}
& (1+n) k_{t+1}=s\left(r\left(k_{t+1}\right), w\left(k_{t}\right)\right)+v_{t} \\
& (1+n) v_{t+1}=\left(1+r\left(k_{t+1}\right)\right) v_{t}
\end{aligned}
$$

Under Assumption $\mathcal{C},\left(\mathrm{E}_{S}^{\prime}\right)$ can be written as

$$
\begin{aligned}
k_{t+1} & =\psi\left(k_{t}, v_{t}\right) \\
v_{t+1} & =\frac{1-\beta+f^{\prime}\left(\psi\left(k_{t}, v_{t}\right)\right)}{1+n} v_{t}
\end{aligned}
$$

where $\psi: \mathbb{R}_{t}^{2} \longrightarrow \mathbb{R}$ is an increasing, differentiable function. ( $\left.\mathrm{E}_{S}^{\prime \prime}\right)$ is a difference equation system which has been extensively studied in the OLG literature ${ }^{6}$ in the case where $v_{t} \leq 0$ : in the present setting we are interested in the polar case $v_{t} \geq 0$. The phase diagram is determined by the curves $\mathcal{V}$ and $\mathcal{K}$ defined by

$$
\begin{aligned}
\mathcal{V} & =\left\{\left(k_{t}, v_{t}\right) \in \mathbb{R}_{+}^{2} \mid v_{t+1}=v_{t}\right\}=\left\{\left(k_{t}, v_{t}\right) \in \mathbb{R}_{+}^{2} \mid v_{t}=0 \text { or } \psi\left(k_{t}, v_{t}\right)=k^{*}\right\} \\
& =\left\{\left(k_{t}, v_{t}\right) \in \mathbb{R}_{+}^{2} \mid v_{t}=0 \text { or } v_{t}=(1+n) k^{*}-s\left(r^{*}, w\left(k_{t}\right)\right)\right\}
\end{aligned}
$$

and

$$
\mathcal{K}=\left\{\left(k_{t}, v_{t}\right) \in \mathbb{R}_{+}^{2} \mid k_{t+1}=k_{t}\right\}=\left\{\left(k_{t}, v_{t}\right) \in \mathbb{R}^{2} \mid v_{t}=(1+n) k_{t}-s\left(r\left(k_{t}\right), w\left(k_{t}\right)\right)\right\}
$$

Under assumptions $(\mathcal{C}, \mathcal{S}), \mathcal{V}$ is the union of the axis $v=0$ and the graph of a decreasing function, while $\mathcal{K}$ is a $U$-shaped curve passing through the origin. The resulting phase diagrams for an economy with overaccumulation and underaccumulation are shown in Figure 1(a) and (b).

As Figure 1(a) suggests, the Diamond steady state $k_{D}$ is globally stable for an economy with overaccumulation.

Proposition 4: Under assumptions $(\mathcal{C}, \mathcal{S})$, if $k^{*}<k_{D}$ then any solution $\left(k_{t}, v_{t}\right)_{t \geq 0}$ of $\left(E_{S}^{\prime \prime}\right)$ with $k_{0}>0, v_{0} \geq 0$ converges to $\left(k_{D}, 0\right)$.

\footnotetext{
${ }^{6}$ See for example Tirole (1985), Azariadis (1993)
} 


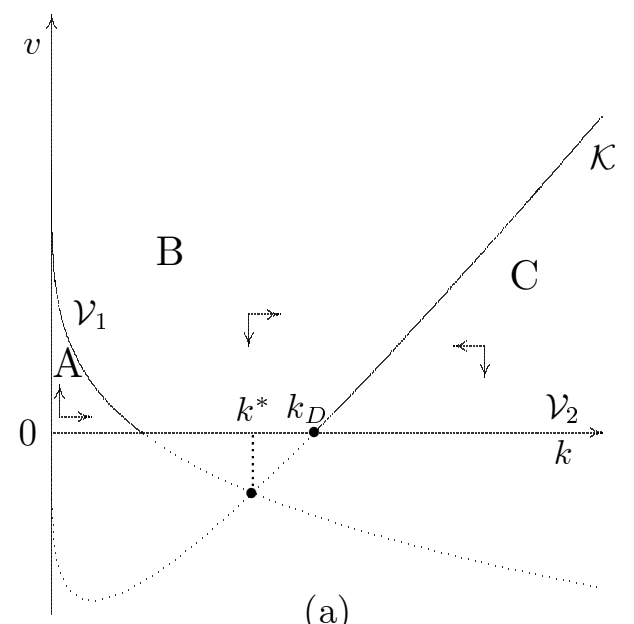

(a)

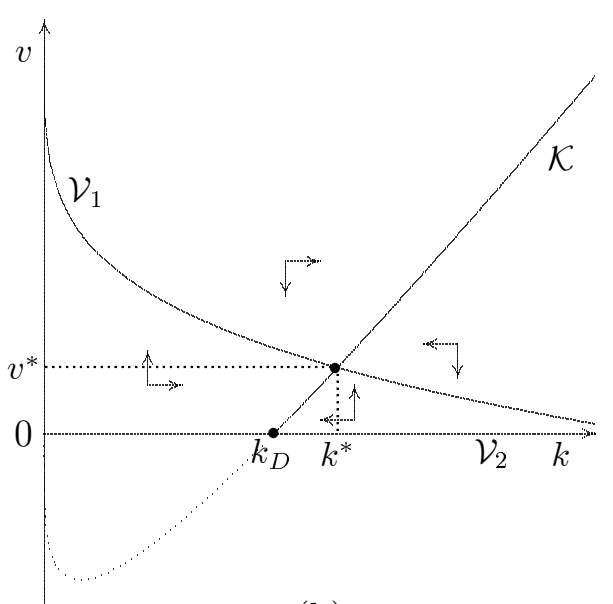

(b)

Figure 1: Phase diagram for the stock market equilibrium equations $\left(E_{S}^{\prime \prime}\right)$ in the cases of (a) overaccumulation and (b) underaccumulation.

PROOF: If $v_{0}=0$, then by Proposition 3 , the trajectory converges to the Diamond steady state. If $v_{0}>0$ and $\left(k_{0}, v_{0}\right) \in B \cup C$, then it is clear from the phase portrait (Figure 1(a)) that $\left(k_{t}, v_{t}\right) \in B \cup C$ for all $t \geq 0$. Furthermore the sequence $\left(v_{t}\right)_{t \geq 0}$ is a decreasing sequence which is bounded below since $v_{t}>0, \forall t \geq 0$ : thus $v_{t} \longrightarrow \bar{v}$. Either $\bar{v}>0$ or $\bar{v}=0$. Suppose $\bar{v}>0$ then $k_{t} \longrightarrow \bar{k}$ defined by $\bar{v}=\frac{1}{1+n}\left(1-\beta+f^{\prime}(\psi(\bar{k}, \bar{v}))\right) \bar{v} \Longleftrightarrow \psi(\bar{k}, \bar{v})=k^{*}$ so that $(\bar{k}, \bar{v})$ lies on the curve $\mathcal{K}$. Since there is no intersection of the $\mathcal{V}_{1}$ curve and the $\mathcal{K}$ curve in the non-negative orthant, it follows that $\bar{v} \in \mathcal{V}_{2}$. Thus $\bar{v}=0$ and $\bar{k}=k_{D}$.

If $v_{0}>0$ and $\left(k_{0}, v_{0}\right) \in A$, since both components increase uniformly, the trajectory leaves the region $A$ in a finite number of periods and must enter region $B$. The previous reasoning shows that $\left(k_{t}, v_{t}\right) \longrightarrow\left(k_{D}, 0\right)$.

The condition for positive investment by the young requires that the initial condition $\left(k_{0}, v_{0}\right)$ satisfy (IC), namely $\left(1+r\left(k_{0}\right)\right) v_{0}<(1-\beta)^{2} k_{0} \Longleftrightarrow(1+n) v_{1} \leq(1-\beta)^{2} k_{0}$. If $k_{0}<k_{D}$ then the equilibrium condition (vi), $(1+n) v_{t+1} \leq(1-\beta)^{2} k_{t}$ holds for all $t \geq 0$ since $\left(v_{t}\right)_{t \geq 0}$ is decreasing and $k_{t} \geq k_{t}^{D} \geq k_{0}$ for all $t \geq 0$, where $k_{t}^{D}$ denotes the capital stock on the Diamond trajectory starting at $\left(k_{0}, 0\right)$. If $k_{0} \geq k_{D}$ it suffices to have initial conditions such that $\left(1+r\left(k_{0}\right)\right) v_{0} \leq(1-\beta)^{2} k_{D}$ to have $(1+n) v_{t+1} \leq(1-\beta)^{2} k_{t}$ on the whole trajectory, since $\left(v_{t}\right)_{t \geq 0}$ is decreasing and $k_{t} \geq k_{t}^{D} \geq k_{D}$. Thus in the case of overaccumulation it is easy to prove the existence of a stock market equilibrium trajectory and its convergence to the Diamond equilibrium. In this case the existence of a discount 
on equity does not improve the long-run efficiency of the equilibrium. This was to be expected since in the case of overaccumulation the propensity to save of the young agents is too high when compared to the productivity of capital. The discount on equity which is akin to an increase in savings can only make things worse. In the long run however the effect vanishes, since the discount on equity increases at a slower rate than the population and tends to disappear in per-capita terms, so that the equilibrium converges to the stable Diamond steady state. A variety of methods have been proposed for absorbing the excess savings and restore convergence to the Golden Rule: social security, land as a third factor of production (McCallum (1987), Rhee (1991)) or unbacked debt (Pingle-Tesfatsion (1998)): each of these methods is applicable to our model.

For an economy with underaccumulation, the savings of the young are "scarce" and the discount on the equity prices acts like an additional source of funds, permitting increased investment. The phase diagram (Figure 1(b)) suggests that the equilibrium trajectories converge to the Golden Rule steady state. Global properties are more difficult to establish for economies with underaccumulation than for those with overaccumulation. Indeed even to prove the local stability of the Golden Rule $\left(k^{*}, v^{*}\right)$, a stronger assumption is needed than that which assures the stability of the Diamond steady state under the Diamond dynamics, namely assumption $(\mathcal{C}, \mathcal{S})$.

Assumption $\mathcal{P}$. The production function $f$ is such that $k f^{\prime}(k)$ is an increasing function of $k$.

$\mathcal{P}$ is satisfied only if capital and labor are sufficiently substitutable: it requires that the marginal product of capital $f^{\prime}(k)$ does not decrease too fast as the capital-labor ratio $k$ increases, so that the amount of output (per capita) going as payment to capital $\left(k f^{\prime}(k)\right)$ decreases. This property is satisfied for CES production functions $F(K, L)$ with elasticity of substitution greater than or equal to 1 (and hence for Cobb-Douglas production functions): thus for the class of CES functions $\mathcal{P}$ requires no additional restrictions over those needed to satisfy assumption $\mathcal{S}$.

Proposition 5: Under assumptions $(C, \mathcal{S}, \mathcal{P})$, if $k^{*}>k_{D}$ then under the stock market equilibrium dynamics $\left(E_{S}^{\prime \prime}\right)$, the Golden Rule $\left(k^{*}, v^{*}\right)$ is locally stable and the Diamond steady state $\left(k_{D}, 0\right)$ is locally saddlepoint stable.

Proof: The difference equation system $\left(\mathrm{E}_{S}^{\prime \prime}\right)$ can be written as

$$
\begin{aligned}
& k_{t+1}=\psi\left(k_{t}, v_{t}\right) \\
& v_{t+1}=h\left(k_{t}, v_{t}\right)
\end{aligned}
$$


where $\psi$ is defined implicitly by the equation

$$
(1+n) \psi\left(k_{t}, v_{t}\right)-s\left(f^{\prime}\left(\psi\left(k_{t}, v_{t}\right)\right)-\beta, w\left(k_{t}\right)\right)-v_{t}=0
$$

and $h\left(k_{t}, v_{t}\right)=g\left(\psi\left(k_{t}, v_{t}\right)\right) v_{t}$ with $g(x)=\frac{1-\beta+f^{\prime}(x)}{1+n}$. Thus the linearized system associated with $\left(\mathrm{E}_{S}^{\prime \prime}\right)$ around a steady state $(\bar{k}, \bar{v})$, expressed in terms of the deviation variables $\left(\kappa_{t}, \nu_{t}\right)=\left(k_{t}-\right.$ $\left.\bar{k}, v_{t}-\bar{v}\right)$ is given by

$$
\left[\begin{array}{l}
\kappa_{t+1} \\
\nu_{t+1}
\end{array}\right]=\left[\begin{array}{ll}
\psi_{k}^{\prime}(\bar{k}, \bar{v}) & \psi_{v}^{\prime}(\bar{k}, \bar{v}) \\
h_{k}^{\prime}(\bar{k}, \bar{v}) & h_{v}^{\prime}(\bar{k}, \bar{v})
\end{array}\right]\left[\begin{array}{c}
\kappa_{t} \\
\nu_{t}
\end{array}\right]
$$

where

$$
\begin{aligned}
\psi_{k}^{\prime}(\bar{k}, \bar{v}) & =\frac{-s_{w}^{\prime} \bar{k} f^{\prime \prime}(\bar{k})}{1+n-s_{r}^{\prime} f^{\prime \prime}(\bar{k})}, & \psi_{v}^{\prime}(\bar{k}, \bar{v}) & =\frac{1}{1+n-s_{r}^{\prime} f^{\prime \prime}(\bar{k})} \\
h_{k}^{\prime}(\bar{k}, \bar{v}) & =\frac{f^{\prime \prime}(\bar{k})}{1+n}\left(\frac{-s_{w}^{\prime} \bar{k} f^{\prime \prime}(\bar{k})}{1+n-s_{r}^{\prime} f^{\prime \prime}(\bar{k})}\right) \bar{v}, & h_{v}^{\prime}(\bar{k}, \bar{v}) & =g(\bar{k})+\frac{f^{\prime \prime}(\bar{k}) \bar{v}}{(1+n)\left(1+n-s_{r}^{\prime} f^{\prime \prime}(\bar{k})\right)}
\end{aligned}
$$

Let $\bar{M}$ denote the matrix of coefficients in $\left(\mathrm{L}_{S}\right)$ evaluated at $(\bar{k}, \bar{v})$, and let $p(\lambda)=\lambda^{2}-\operatorname{tr}(\bar{M}) \lambda+$ $\operatorname{det} \bar{M}=0$ denote the associated characteristic polynomial. To show that the Golden Rule steady state $(\bar{k}, \bar{v})=\left(k^{*}, v^{*}\right)$ is locally stable we show that both roots of the characteristic polynomial lie inside the unit circle $\left(\left|\lambda_{i}\right|<1, i=1,2\right)$. Note that $\operatorname{det} M^{*}=\psi_{k}^{\prime}\left(k^{*}, v^{*}\right)=\frac{-s_{w}^{\prime} k^{*} f^{\prime \prime}\left(k^{*}\right)}{1+n-s_{r}^{\prime} f^{\prime \prime}\left(k^{*}\right)}>0$ by assumption $\mathcal{C}$. Since there is underaccumulation, $k^{*}>k_{D}$ and by assumption $\mathcal{S}, S^{\prime}\left(k^{*}\right)<\frac{S\left(k_{D}\right)}{k_{D}}=$ $1+n$. Since $S^{\prime}\left(k^{*}\right)=s_{r}^{\prime} f^{\prime \prime}\left(k^{*}\right)-s_{w}^{\prime} k^{*} f^{\prime \prime}\left(k^{*}\right)$, this implies $0<\operatorname{det} M^{*}<1$. Since $\operatorname{det} M^{*}=\lambda_{1} \lambda_{2}$, if both roots are complex, they lie inside the unit circle. The condition $0<\operatorname{det} M^{*}<1$ implies that if both roots are real they lie in the unit interval $(-1,1)$ if and only if $p(1)>0$ and $p(-1)>0$. Now

$$
p(1)=1-\operatorname{tr} M^{*}+\operatorname{det} M^{*}=\frac{-f^{\prime \prime}\left(k^{*}\right) v^{*}}{(1+n)\left(1+n-s_{r}^{\prime} f^{\prime \prime}\left(k^{*}\right)\right)}>0
$$

since $v^{*}>0, s_{r}^{\prime} \geq 0, f^{\prime \prime}\left(k^{*}\right)<0$ and

$$
p(-1)=1+\operatorname{tr} M^{*}+\operatorname{det} M^{*}=2-\frac{2 s_{w}^{\prime} k^{*} f^{\prime \prime}\left(k^{*}\right)}{1+n-s_{r}^{\prime} f^{\prime \prime}\left(k^{*}\right)}+\frac{f^{\prime \prime}\left(k^{*}\right) v^{*}}{(1+n)\left(1+n-s_{r}^{\prime} f^{\prime \prime}\left(k^{*}\right)\right)}
$$

The first two terms are positive: to show $p(-1)>0$ it suffices to show that the third term is bounded below by -1 . Since $S\left(k^{*}\right)>0, v^{*}<(1+n) k^{*}$ and since assumption $\mathcal{P}$ implies $k^{*} f^{\prime \prime}\left(k^{*}\right) \geq$ $-f^{\prime}\left(k^{*}\right)=-(\beta+n)$, it follows that

$$
\frac{f^{\prime \prime}\left(k^{*}\right) v^{*}}{(1+n)\left(1+n-s_{r}^{\prime} f^{\prime \prime}\left(k^{*}\right)\right)}>\frac{f^{\prime \prime}\left(k^{*}\right) k^{*}}{1+n-s_{r}^{\prime} f^{\prime \prime}\left(k^{*}\right)} \geq \frac{-f^{\prime}\left(k^{*}\right)}{1+n-s_{r}^{\prime} f^{\prime \prime}\left(k^{*}\right)}>-\frac{(\beta+n)}{1+n}>-1
$$

Thus both roots lie inside the unit circle and $\left(k^{*}, v^{*}\right)$ is locally stable. 
At the Diamond steady state $(\bar{k}, \bar{v})=\left(k_{D}, 0\right), h_{k}^{\prime}\left(k_{D}, 0\right)=0$ so that $M_{D}$ is triangular and $P(\lambda)=\left(\psi_{k}^{\prime}\left(k_{D}, 0\right)-\lambda\right)\left(h_{v}^{\prime}\left(k_{D}, 0\right)-\lambda\right)$. Since $0<\psi_{k}^{\prime}\left(k_{D}, 0\right)=-\frac{-s_{w}^{\prime} k_{D} f^{\prime \prime}\left(k_{D}\right)}{1+n-s^{\prime} f^{\prime \prime}\left(k_{D}\right)}<1$ where the latter inequality follows from $S^{\prime}\left(k_{D}\right)<\frac{S\left(k_{D}\right)}{k_{D}}=1+n$, and $h_{v}^{\prime}\left(k_{D}, 0\right)=g\left(k_{D}\right)=\frac{1+r\left(k_{D}\right)}{1+n}>1$, it follows that the Diamond steady state is locally saddlepoint stable.

Proposition 5 implies that for all economies satisfying assumption $\mathcal{S}^{*}$, a stock market equilibrium which converges to the Golden Rule exists for all initial conditions $\left(k_{0}, v_{0}\right)$ in a neighborhood of the Golden Rule $\left(k^{*}, v^{*}\right)$. Assumption $\mathcal{S}^{*}$ in essence imposes a restriction on how far the Diamond steady state $k_{D}$ is from the Golden Rule $k^{*}$ : if $k^{*}$ is too much greater than $k_{D}$ then the funds in excess of the savings of the young needed to finance investment become too large to permit them to be covered by the discount on the equity prices. To get a feel for how the equilibrium behaves and to what extent these conditions are restrictive, let us consider a family of Cobb-Douglas economies.

Example: Let $\mathcal{E}(u, F, n)$ be a Cobb-Douglas economy:

$$
u\left(c_{0}, c_{1}\right)=c_{0}^{1-\alpha} c_{1}^{\alpha}, \quad 0<\alpha<1, \quad F(K, L)=A K^{\gamma} L^{1-\gamma}, \quad 0<\gamma<1
$$

There are four parameters $(\alpha, \gamma, \beta, n)$ which characterize an economy: the parameter $A$ is just a scale factor which does not matter for the analysis (we choose $A=50$ ). $\alpha$ gives the propensity to save of the young $(s(r, w)=\alpha w), \gamma$ determines the share of capital in output, $0<\beta<1$ is the depreciation rate of capital and $n$ the population growth rate. Let us fix $\gamma=0.25$ and $n=0.35$ (which corresponds to an annual increase of population of about $1 \%$ for 30 years). The Golden Rule capital-labor ratio is $k^{*}=\left(\frac{A \gamma}{\beta+n}\right)^{\frac{1}{1-\gamma}}$ and there is underaccumulation if

$$
(1+n) k^{*} \geq A \alpha(1-\gamma)\left(k^{*}\right)^{\gamma} \Longleftrightarrow(1+n) \geq \frac{\alpha(1-\gamma)}{\gamma}(\beta+n) \Longleftrightarrow \alpha \leq \frac{\gamma(1+n)}{(1-\gamma)(\beta+n)}
$$

The Golden Rule $k^{*}$ satisfies condition $\left(\mathrm{IC}^{\prime}\right)$ if

$$
A \alpha(1-\gamma)\left(k^{*}\right)^{\gamma} \geq(\beta+n) k^{*}+\frac{1-\beta}{1+n}(\beta+n) k^{*} \Longleftrightarrow \alpha \geq \frac{\gamma}{1-\gamma}+\frac{(1-\beta)^{2}}{1+n} \frac{\gamma}{1-\gamma}
$$

For the chosen parameters $(\gamma, n)=(0.25,0.35),(24)$ and $(25)$ give the admissible values of the parameters $(\alpha, \beta) \in(0,1) \times(0,1)$ for which the Golden Rule is a stock market equilibrium. Let $\ell(\beta)=\frac{\gamma}{1-\gamma}\left(\frac{1+n}{\beta+n}\right)$ denote the function in (24) defining economies with "low" savings (underaccumulation) and let $p(\beta)=\frac{\gamma}{1-\gamma}\left(1+\frac{(1-\beta)}{1+n}\right)$ denote the function in (25) defining economies in which there is "positive" investment, then the admissible parameters $(\alpha, \beta)$ are given by the shaded region 


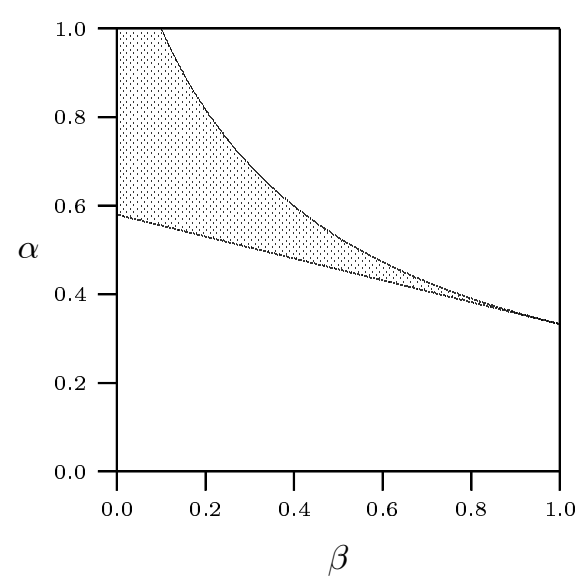

(a)

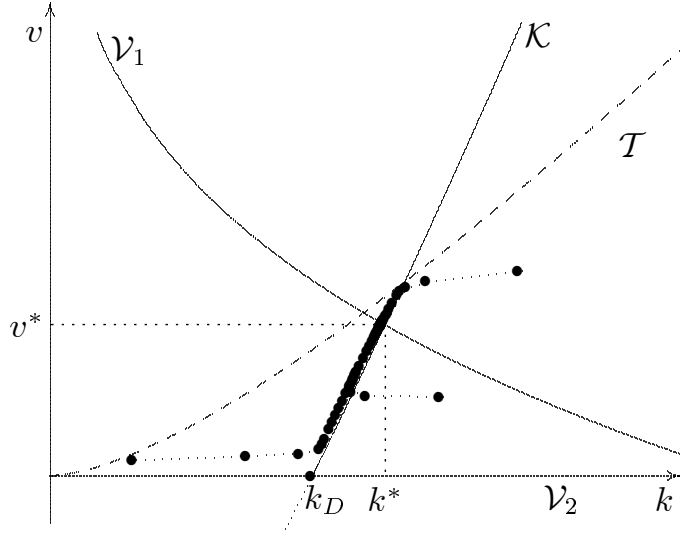

(b)

Figure 2: (a) parameters for which the Cobb-Douglas economy is characterized by underaccumulation and satisfies $\mathcal{S}^{*}$; (b) convergence of the trajectories to the Golden Rule.

in Figure 2(a). Thus, for example, if $\beta=0.4$ (which corresponds to an annual depreciation rate of $1.7 \%$ for 30 years) then the interval of admissible $\alpha$ values is $[0.48,0.6]$. Figure 2(b) shows equilibrium trajectories when $(\alpha, \beta)=(0.5,0.4)$. The region lying below the dashed curve $\mathcal{T}$ defines the set of $\left(k_{t}, v_{t}\right)$ pairs satisfying condition $\mathrm{E}(\mathrm{vi})$ which ensures that the young have the incentive to make positive investment in their firms. For every initial condition satisfying (IC), the trajectory satisfies $\mathrm{E}$ (vi) for all $t \geq 0$ and converges to the Golden Rule.

\section{Adding Financial Intermediaries.}

One might conclude from the example of the previous section that the conditions under which economies with underaccumulation have a stock market equilibrium with positive investment and a discount on the equity prices of firms $\left(v_{t}>0\right)$ is somewhat restrictive. This section shows that if we assume borrowing and lending can take place through infinitely-lived intermediaries, then the restriction imposed by assumption $\mathcal{S}^{*}$ disappears, and all economies with underaccumulation satisfying assumptions $(\mathcal{C}, \mathcal{S}, \mathcal{P})$ have stock market equilibria with positive discounts on the equity prices of firms for appropriate initial conditions.

Suppose therefore that there are financial intermediaries (banks) which receive the savings of the young as deposits and make loans to the firms. Assuming that there is perfect competition among the intermediaries the financial sector can, without loss of generality, be represented by a 
single bank making zero profit on its constant returns intermediation activity. At each date the bank receives that part of the savings of the young $N_{t}\left(s\left(r\left(k_{t+1}\right), w\left(k_{t}\right)\right)-q_{t}\right)$ which is not spent on the stock market for buying the firms; in addition it receives the reimbursements $N_{t-1}(1+$ $\left.r\left(k_{t}\right)\right) i_{t-1}$ of the firms that had borrowed in the previous period $(t-1)$. A part of these funds, $N_{t-1}\left(\left(1+r\left(k_{t}\right)\right) s\left(r\left(k_{t}\right), w\left(k_{t-1}\right)\right)-q_{t-1}\right)$, is used to reimburse the old agents who saved in the previous period, and the remainder is lent to the firms to finance their new investment at date $t$, $N_{t} i_{t}$. Thus equation (vii), $s\left(r_{t+1}, w_{t}\right)=q_{t}+i_{t}$ of Definition 1, which required that borrowing and lending be intragenerational, is replaced by the budget constraint of the intermediary

$$
(1+n)\left(q_{t}+i_{t}-s\left(r\left(k_{t+1}\right), w\left(k_{t}\right)\right)=\left(1+r\left(k_{t}\right)\right)\left(q_{t-1}+i_{t-1}-s\left(r\left(k_{t}\right), w\left(k_{t-1}\right)\right)\right)\right.
$$

which can also be written as

$$
(1+n) v_{t}^{b}=\left(1+r\left(k_{t}\right)\right) v_{t-1}^{b}
$$

with

$$
v_{t}^{b}=i_{t}-\left(s\left(r\left(k_{t+1}\right), w\left(k_{t}\right)\right)-q_{t}\right)
$$

denoting the lending of the intermediary (to the firms) in excess of the deposits of the young. Note that $v_{t}^{b}>0$ is possible if the reimbursement of the firms exceeds what is required to pay back the old agents.

Let us modify slightly the notation of the previous section and let $v_{t}^{s}$ denote the discount on the (per-capita) equity price $q_{t}$ of the firms

$$
q_{t}=(1-\beta) k_{t}-v_{t}^{s}
$$

which must satisfy conditions (v) and (vi) of Definition 1

$$
\begin{aligned}
& (1+n) v_{t+1}^{s}=\left(1+r\left(k_{t+1}\right)\right) v_{t}^{s} \\
& 0 \leq(1+n) v_{t+1}^{s} \leq(1-\beta)^{2} k_{t}
\end{aligned}
$$

Substituting the expression (28) for $q_{t}$ and (iii) of (E) for $i_{t}$ leads to

$$
(1+n) k_{t+1}=s\left(r\left(k_{t+1}\right), w\left(k_{t}\right)\right)+v_{t}
$$

with $v_{t}=v_{t}^{s}+v_{t}^{b}$.

Since by (26) and (29), $v_{t}=v_{t}^{s}+v_{t}^{b}$ satisfies

$$
(1+n) v_{t+1}=\left(1+r\left(k_{t+1}\right)\right) v_{t}
$$


the equilibrium with intermediaries and a stock market is determined by the same difference equation system $\left(\mathrm{E}_{S}^{\prime}\right)$ as the stock market equilibrium of the previous section. The only difference is that the "work" of providing funds for the investment of firms over and above the savings of consumers is shared between the stock market (through the discount on equity) and the intermediaries (through the excess reimbursement of firms.). The relative magnitude of $\left(v_{t}^{s}, v_{t}^{b}\right)$ is determined by the initial conditions. An initial condition $v_{0}^{b}>0$ is essentially a way of capturing the fact that depository institutions like banks have the ability to create loanable funds out of the (here unmodelled) random process of deposits and withdrawals of short-term transactions balances by their customers. If $v_{0}^{s}=\mu v_{0}$ then at the steady state $v^{s *}=\mu v^{*}$. In order that (30) be satisfied at the steady state $k^{*}, \mu$ must be such that $\mu<\frac{(1-\beta)^{2}}{1+n} \frac{k^{*}}{v^{*}}$. Thus if $v_{0}^{b}>0$, there is always an initial condition $v_{0}^{s}$ such that (30) is satisfied on a trajectory $\left(k_{t}, v_{t}\right)_{t \geq 0}$ induced by $\left(\mathrm{E}_{s}^{\prime}\right)$ converging to the Golden Rule $\left(k^{*}, v^{*}\right)$.

\section{Stock Market Prices.}

In this section we examine the properties of equity prices in a stock market equilibrium. We begin with the case of an economy with underaccumulation which is the easiest to analyze. The basic no-arbitrage pricing equation leads after successive substitutions to the expression

$$
Q_{t}=\sum_{\tau=1}^{T} \frac{D_{t+\tau}}{\left(1+r_{t+1}\right) \ldots\left(1+r_{t+\tau}\right)}+\frac{Q_{t+T}}{\left(1+r_{t+1}\right) \ldots\left(1+r_{t+T}\right)}
$$

If the series of discounted dividends converges (as shown in the next proposition), then $Q_{t}$ can be written as

$$
Q_{t}=\mathbb{F}_{t}+\mathbb{B}_{t}
$$

where

$$
\mathbb{F}_{t}=\sum_{\tau=1}^{\infty} \frac{D_{t+\tau}}{\left(1+r_{t+1}\right) \ldots\left(1+r_{t+\tau}\right)} \quad \text { and } \mathbb{B}_{t}=\lim _{T \longrightarrow \infty} \frac{Q_{t+T}}{\left(1+r_{t+1}\right) \ldots\left(1+r_{t+T}\right)}
$$

$\mathrm{F}_{t}$ is the fundamental value of the equity (i.e. the present value of its future dividend stream) and $\mathrm{B}_{t}$ is the bubble component of the price. $\mathrm{B}_{t}$ satisfies (2) with $D_{t+1}=0$, namely the bubble equation $\mathrm{B}_{t+1}=\left(1+r_{t+1}\right) \mathrm{B}_{t}$, so that the bubble grows at the rate of interest.

A heuristic argument, showing that on any equilibrium trajectory which converges to the Golden Rule, the equity price must have a bubble $\left(\mathbb{B}_{t}>0\right)$, runs as follows: (32) can be written as $q_{t}=\frac{Q_{t}}{N_{t}}=\frac{\mathbb{F}_{t}}{N_{t}}+\frac{\mathbb{B}_{t}}{N_{t}}$. Since the equilibrium converges to the Golden Rule, $q_{t} \longrightarrow q^{*}$ and $\frac{\mathbb{F}_{t}}{N_{t}} \longrightarrow \frac{\mathbb{F}^{*}}{N_{t}}$ 
where $\mathbb{F}^{*}$ is the present value of the dividend stream at $k^{*}$, so that $\frac{\mathbb{B}_{t}}{N_{t}} \longrightarrow q^{*}-\frac{\mathbb{F}^{*}}{N_{t}}$. But the dividends at the Golden Rule are zero for ever since

$$
D_{t+1}^{*}=N_{t+1}\left(f\left(k^{*}\right)-w^{*}-\frac{(1+n) i^{*}}{1+n}\right)=N_{t+1}\left(k^{*} f^{\prime}\left(k^{*}\right)-(\beta+n) k^{*}\right)=0
$$

Thus $\mathrm{F}^{*}=0$ and $\frac{\mathrm{B}_{t}}{N_{t}} \longrightarrow q^{*}$. At the Golden Rule the fundamental value of equity is zero since there are never any dividends: all current profit is used to finance investment. Paying a positive price for equity is justified solely because the young agents buying a firm are confident that they will receive a positive price when they come to sell it in the subsequent period: equity has value purely by virtue of its role as a store of value.

Proposition 6: Equity prices $\left(Q_{t}\right)_{t \geq 0}$ in a stock market equilibrium of an economy with underaccumulation have the following properties:

(i) If $v_{0}>0$ and the equilibrium converges to the Golden Rule, then at every date there is a bubble component: $Q_{t}=\mathrm{F}_{t}+\mathbb{B}_{t}$ with $\mathbb{B}_{t}>0$, for all $t \geq 0$.

(ii) If $v_{0}=0$ and the equilibrium converges to the Diamond equilibrium, then at every date the price is equal to its fundamental value: $Q_{t}=\mathbb{F}_{t}$ with $\mathbb{B}_{t}=0$ for all $t \geq 0$.

Proof: (i) Let $\left(k_{t}, v_{t}\right)_{t \geq 0}$ be a stock market equilibrium satisfying $\left(\mathrm{E}_{S}^{\prime}\right)$ such that $\left(k_{t}, v_{t}\right) \longrightarrow$ $\left(k^{*}, v^{*}\right)$. Let us prove the result for the general case where there can be intermediaries on the bond market, so that $v_{t}=v_{t}^{s}+v_{t}^{b}$ and $v_{t}^{s}$ satisfies (29) and (30). The dividends at date $t+1$ are

$$
\begin{aligned}
D_{t+1} & =N_{t}\left((1+n) k_{t+1} f^{\prime}\left(k_{t+1}\right)-\left(1+r_{t+1}\right) i_{t}\right) \\
& =N_{t}(1-\beta)\left(\left(1+r_{t+1}\right) k_{t}-(1+n) k_{t+1}\right)
\end{aligned}
$$

so that $D_{t+\tau}=N_{t}(1-\beta)\left((1+n)^{\tau-1}\left(1+r_{t+\tau}\right) k_{t+\tau-1}-(1+n)^{\tau} k_{t+\tau}\right)$ and

$$
\frac{1}{N_{t}} \sum_{\tau=1}^{T} \frac{D_{t+\tau}}{\left(1+r_{t+1}\right) \ldots\left(1+r_{t+\tau}\right)}=(1-\beta)\left(k_{t}-\frac{(1+n)^{T} k_{t+T}}{\left(1+r_{t+1}\right) \ldots\left(1+r_{t+T}\right)}\right)
$$

The recursive equations $\left(\mathrm{E}_{S}^{\prime}\right)$ imply $\frac{(1+n)^{T}}{\left(1+r_{t+1}\right) \ldots\left(1+r_{t+T}\right)}=\frac{v_{t}}{v_{t+T}}$, so that

$$
\frac{\mathrm{F}_{t}}{N_{t}}=(1-\beta) \lim _{T \longrightarrow \infty}\left(k_{t}-\frac{v_{t}}{v_{t+T}} k_{t+T}\right)=(1-\beta) k^{*}\left(\frac{k_{t}}{k^{*}}-\frac{v_{t}}{v^{*}}\right)
$$


since $\left(k_{t+T}, v_{t+T}\right) \longrightarrow\left(k^{*}, v^{*}\right)$. Thus

$$
\begin{aligned}
\frac{\mathrm{B}_{t}}{N_{t}}=q_{t}-\frac{\mathbb{F}_{t}}{N_{t}} & =(1-\beta) k_{t}-v_{t}^{s}-(1-\beta) k^{*}\left(\frac{k_{t}}{k^{*}}-\frac{v_{t}}{v^{*}}\right) \\
& =(1-\beta) k^{*} \frac{v_{t}}{v^{*}}-v_{t}^{s}
\end{aligned}
$$

If $v_{t}^{s}=0$, since $v_{t}$ must be positive, $\mathrm{B}_{t}>0$ for all $t \geq 0$. If $v_{t}^{s}>0, \frac{v_{t}}{v^{*}}=\frac{v_{t}^{s}}{v^{s *}}$ : since (30) is satisfied at $\left(k^{*}, v^{s *}\right), v^{s *} \leq \frac{(1-\beta)^{2}}{1+n} k^{*}<(1-\beta) k^{*}$ and $\mathbb{B}_{t}>0$ for all $t \geq 0$.

(ii) Formula (34) also applies on a Diamond trajectory with $v_{0}=0$. Since $r_{t+T} \longrightarrow r_{D}>n$, $\lim _{T \longrightarrow \infty} \frac{(1+n)^{T}}{\left(1+r_{t+1}\right) \ldots\left(1+r_{t+T}\right)}=0$, so that $\frac{\mathrm{F}_{t}}{N_{t}}=(1-\beta) k_{t}$ and $\mathbb{B}_{t}=0$ for all $t \geq 0$.

Analyzing the two components of equity value (35) and (36), we see that if a trajectory begins with a low capital-labor ratio and a small transfer (i.e. $\left(k_{0}, v_{0}\right)$ small), on the initial segment of the trajectory the price of equity is not very different from the replacement cost of capital $\left(v_{t} / v^{*}\right.$ small) and is essentially determined by the fundamental value of the dividends $\left(\mathbb{B}_{t} / N_{t}\right.$ small). Interest rates are high, investment is small and dividends are significant. As the economy grows, the capital-labor ratio increases and the trajectory approaches the Golden Rule: dividends tend to disappear $\left(k_{t} / k^{*} \simeq 1, v_{t} / v^{*} \simeq 1\right.$ and $\left.k_{t} / k^{*}-v_{t} / v^{*} \simeq 0\right)$ and equity prices are essentially determined by the transmission value of equity, i.e. its role as an instrument for the transfer of ownership from one generation to the next. The extent to which the equity prices differ from the replacement value of the capital near the Golden Rule depends on the relative importance of the intermediary sector and the discount on equity in providing the requisite savings. Note that when the "work" is done entirely through intermediation $\left(v_{t}^{s}=0\right)$ we obtain the rather striking result that as the economy approaches the Golden Rule the financial price of a firm is equal to the real value of its capital, and yet there is no fundamental in the sense of finance to support the valuation, all value being derived from the role of equity as a store of value.

In an economy with underaccumulation, investment is productive and firms earn enough to pay off their debt each period: thus in the above calculations we evaluated the equity price of a firm assuming that it incurs no long-term debt. It should be noted that the fundamental value $\mathbb{F}_{t}$ would not change if the firm were to resort to long-term debt after date $t$, provided that such debts are paid back in finite time: for all the associated dividend streams have the same present value.

In an economy with overaccumulation, investment is much less productive and an analysis of formulae (33) and (34) reveals that in this case firms do not earn enough to pay off their debt each period and distribute non-negative dividends to their shareholders. Indeed any method of financing using debts that are paid off in finite time gives rise to negative dividends since it does not change 
the present value of the associated dividend stream. Thus in an economy with overaccumulation, the only way for a firm to pay non-negative dividends is to roll over its debts to infinity - a policy which is feasible since the rate of interest is less than the rate of growth of the economy.

Consider therefore an equilibrium trajectory of an economy with overaccumulation which converges to the Diamond equilibrium, $k_{t} \longrightarrow k_{D}$ : since $r_{t+T} \longrightarrow r_{D}<n$, the sequence of partial sums in (34) defining the fundamental value of the firm with no long-term debt converges to $-\infty$. If the firm tried to pay off its debt each period (or even in a finite number of periods), since its current investment costs exceed its current profit, it would have to call on the shareholders to finance the difference. Since limited liability requires that dividends be non-negative, all such strategies are unfeasible: instead the firm — to finance its high-cost low-yield investment — must roll over its debt to infinity.

Suppose that the firm decides to pay no dividends at each date, and finances the excess of its current investment costs over its current profit by issuing long-term debt which it rolls over indefinitely. When date $t$ arrives, the debt $\Delta_{t}$ which it will have accumulated is

$$
\Delta_{t}=\sum_{\tau=1}^{t} N_{\tau-1}(1-\beta)\left((1+n) k_{\tau}-\left(1+r_{\tau}\right) k_{\tau-1}\right)\left(1+r_{\tau+1}\right) \ldots\left(1+r_{t}\right)
$$

which after canceling terms reduces to

$$
\Delta_{t}=N_{t}(1-\beta) k_{t}-N_{0}(1-\beta) k_{0}\left(1+r_{1}\right) \ldots\left(1+r_{t}\right)
$$

Let $Q_{t}^{\Delta}$ denote the value of the firm when its (accumulated) debt at date $t$ is $\Delta_{t}$. Since $Q_{t}$ in (14) is the value of the firm when it has zero debt, it follows that

$$
Q_{t}^{\Delta}=Q_{t}-\Delta_{t}
$$

Thus

$$
Q_{t}^{\Delta}=N_{0}(1-\beta) k_{0}\left(1+r_{1}\right) \ldots\left(1+r_{t}\right)-N_{t} v_{t}^{s}
$$

and since by $\left(E_{S}^{\prime}\right)$

$$
v_{t}^{s}=\frac{\left(1+r_{1}\right) \ldots\left(1+r_{t}\right) v_{0}^{s}}{(1+n)^{t}}
$$

it follows that

$$
Q_{t}^{\Delta}=N_{0}\left((1-\beta) k_{0}-v_{0}^{s}\right)\left(1+r_{1}\right) \ldots\left(1+r_{t}\right)
$$

Thus $Q_{t}^{\Delta}>0$ is a pure bubble which grows at the rate of interest. As is to be expected in an economy with overaccumulation, since $r_{t} \longrightarrow r_{D}<n$, the bubble per capita $Q_{t}^{\Delta} / N_{t}$ converges to zero. 
The valuation of firms in a stock market equilibrium stands in striking contrast to the valuations predicted by many of the general equilibrium models of financial economics. Typically financial markets are studied in models with infinitely-lived agents and the conditions on agents' preferences required to establish the existence of equilibrium — namely that agents be impatient — rule out bubbles on equity (Tirole (1982), Magill-Quinzii (1996), Woodford-Santos (1998)). Infinite-lived agent models have moulded the thinking of many economists and the conventional wisdom of the finance literature that security prices are fundamental values.

As Tirole (1985) pointed out the situation is quite different in the OLG framework: Tirole (1985) and Weil (1987) showed that bubbles can arise for infinite-lived securities paying no dividends (such as money viewed purely as a store of value) but only in economies with overaccumulation. The analysis of Tirole, Weil and the ensuing literature on OLG models with production does not establish the existence of bubbles on equity, since there is no equity in these models: in the Diamond framework firms are viewed as short-lived entities which (like their owners) are recreated each period. One might argue that firms in the Diamond model can be long-lived, and that the existence of a second-hand capital goods market forces the financial value of the firm to coincide with the replacement value of its capital, and this is indeed an alternative interpretation of Diamond's model. However, with this interpretation, one cannot deduce from the analysis of Tirole and Weil whether or not there is a bubble on equity: for adding a bubble to the replacement value of a firm's capital cannot be an equilibrium outcome - no young agent would be willing to pay more for a firm than it would cost to purchase the equivalent capital on the goods market.

Our analysis has shown that bubbles on equity are the rule rather than the exception in the $O L G$ model with production, even in economies with underaccumulation. On every equilibrium trajectory there is a bubble, except on the Diamond trajectory of an economy with underaccumulation: in this case, and only in this case, the equity price of a firm coincides with its fundamental value. Since the Diamond steady state is saddlepoint stable, this trajectory is truly exceptional: it is not robust to any deviation of the equity price from the replacement value of the capital or any creation of credit by intermediaries like banks. Since we have shown that a negative deviation (positive discount) of the equity prices of firms is possible and since financial institutions do create credit, the probability that an economy stays on the Diamond trajectory is essentially zero, so that bubbles on equity have to be expected. This result suggests that focusing on fundamentals may not be of much help in deciding whether or not the stock market is currently overvalued. Rather it seems that the rate of growth of equity prices should be the focus of attention. Of course the real world is stochastic and risk premia have to be taken into account in discussing the issue. Extending the framework of 
this model to the setting of a stochastic OLG economy with production is left for future research.

\section{Appendix}

Proof of Proposition 3: A Diamond steady state is a solution of the equation $S(k) / k=1+n$ and it is clear that assumption $\mathcal{S}$ implies that the equation has a unique positive solution $k_{D}$. To prove global stability we show (i) $\phi$ is increasing (ii) $\phi(k)>k$ if $0<k<k_{D}$ and (iii) $\phi(k)<k$ if $k>k_{D}$.

(i) $s\left(r\left(k_{t+1}\right), w\left(k_{t}\right)\right)=(1+n) k_{t+1} \Longleftrightarrow s\left(r\left(\phi\left(k_{t}\right)\right), w\left(k_{t}\right)\right)=(1+n) \phi\left(k_{t}\right) \Longrightarrow s_{r}^{\prime} r^{\prime}\left(k_{t+1}\right) \phi^{\prime}\left(k_{t}\right)+$ $s_{w}^{\prime} w^{\prime}\left(k_{t}\right)=(1+n) \phi^{\prime}\left(k_{t}\right) \Longrightarrow\left[(1+n)-s_{r}^{\prime} f^{\prime \prime}\left(k_{t+1}\right)\right] \phi^{\prime}\left(k_{t}\right)=-s_{w}^{\prime} k_{t} f^{\prime \prime}\left(k_{t}\right) \Longrightarrow$

$$
\phi^{\prime}\left(k_{t}\right)=\frac{-s_{w}^{\prime} k_{t} f^{\prime \prime}\left(k_{t}\right)}{(1+n)-s_{r}^{\prime} f^{\prime \prime}\left(k_{t+1}\right)}>0
$$

(ii) Suppose not, $\phi(k) \leq k$; then $r(\phi(k)) \geq r(k)$ and $s(r(\phi(k)), w(k)) \geq s(r(k), w(k))>(1+$ $n) k \geq(1+n) \phi(k)$ where the first inequality follows from $s_{r}^{\prime} \geq 0$ and the second from $S(k) / k>$ $\frac{S\left(k_{D}\right)}{k_{D}}=(1+n)$ since $k<k_{D}$ : but this contradicts $\left(E_{D}\right)$, namely $s(r(\phi(k)), w(k))=(1+n) \phi(k)$.

(iii) Suppose not, $\phi(k) \geq k$; then $r(\phi(k)) \geq r(k)$ and $s(r(\phi(k)), w(k)) \leq s(r(k), w(k))<$ $(1+n) k \leq(1+n) \phi(k)$, contradicting $\left(E_{D}\right)$.

To complete the proof, suppose $0<k_{0}>k_{D}$ (resp. $k_{0}<k_{D}$ ) then (i)-(iii) imply that $k_{t}$ is an increasing (decreasing) sequence which is bounded above (below) by $k_{D}$ : thus $k_{t} \rightarrow k_{D}$ as $t \rightarrow \infty$.

\section{References}

Abel, A. B. (1999), "The Effects of a Baby Boom on Stock Prices and Capital Accumulation in the Presence of Social Security", NBER Discussion Paper.

Abel, A. B., Mankiw N.G., Summers L.H. and R. J. Zeckhauser (1989), "Assessing Dynamic Efficiency: Theory and Evidence", Review of Economic Studies, 56, 1-20.

Azariadis, C. (1993), Intertemporal Macroeconomics, Cambridge: Blackwell.

Blackstone, W. (1765), Commentaries on the Laws of England, Volume I, Oxford: Clarendon Press. Reprinted by the University of Chicago Press (1979).

Blanchard, O.J. and S. Fischer (1989), Lectures on Macroeconomics, Chapter 3, Cambridge, Mass.: MIT Press. 
Diamond, P.A. (1965), "National Debt in a Neoclassical Growth Model", American Economic Review, 55, 1126-1150.

Gale, D. (1973), "Pure Exchange Equilibrium of Dynamic Economic Models", Journal of Economic Theory, 6, 12-36.

Galor, O. and H.E. Ryder (1989), "Existence, Uniqueness and Stability of Equilibrium in an Overlapping-Generations Model with Productive Capital," Journal of Economic Theory, 49, 360-375.

Gould, J.P. (1968), "Adjustment Costs in the Theory of Investment of the Firm", Review of Economic Studies, 35, 47-56.

Hayashi, F. (1982), "Tobin's Marginal $q$ and Average q: A Neoclassical Interpretation", Econometrica, 50, 213-224.

Lucas, R.E. (1967), "Adjustment Costs and the Theory of Supply", Journal of Political Economy, $75,321-334$.

Magill, M. and M. Quinzii (1996), "Incomplete Markets over an Infinite Horizon: Long-lived Securities and Speculative Bubbles", Journal of Mathematical Economics, 26, 133-170.

McCallum, Bennett T. (1987), "The Optimal Inflation Rate in an Overlapping- Generations Economy with Land", In New Approaches to Monetary Economics, W. A. Barnett and K. J. Singleton eds, Cambridge: Cambridge University Press.

Pingle, M. and L. Tesfatsion (1998), "Active Intermediation in Overlapping Generations Economies with Production and Unsecured Debt", Macroeconomic Dynamics, 2, 183-212.

Rhee, C. (1991), "Dynamic Inefficiency in an Economy with Land", Review of Economic Studies, $58,791-797$.

Santos, M. and M. Woodford (1997), "Rational Asset Pricing Bubbles", Econometrica, 65, 19-57.

Tirole, J. (1982), "On the Possibility of Speculation Under Rational Expectations", Econometrica, 50, 1163-1181.

Tirole, J. (1985), "Asset Bubbles and Overlapping Generations", Econometrica, 53, 1499-1528.

Tobin, J. (1969), "A General Equilibrium Approach to Monetary Theory", Journal of Money, Credit and Banking, 1, 15-29.

Tobin, J. (1998), Money, Credit and Capital, Boston: Irwin McGraw-Hill.

Uzawa, H. (1969), "Time Preference and the Penrose Effect in a Two-Class Model of Economic Growth", Journal of Political Economy, 77, 628-652.

Weil, P. (1987), "Confidence and the Real Value of Money in an Overlapping Generations Economy", Quarterly Journal of Economics, 102, 1-22. 